\title{
Third Generation Flywheels for Electricity Storage
}

Award Number: DE-FG36-05GO15163

June 20, 2008

LaunchPoint Technologies, Inc

5735-B Hollister Ave.,

Goleta, CA 93117

\section{Contact:}

Michael Ricci, 805-683-9659 x244, mricci@launchpnt.com

Jim Fiske, 805-683-9659 x239, jfiske@launchpnt.com

\section{Project Team:}

Michael A. Schledorn, DOE Field Contract Specialist Deborah Weems, DOE Field Project Officer 


\section{Executive Summary}

In the December 1973 issue of Scientific American, Dr. Richard Post of Lawrence Livermore National Laboratory proposed the construction of 200-ton, 10-megawatt-hour composite flywheels to provide electricity storage for the U.S. power grid. Unfortunately, achieving dynamic stability and structural integrity in composite flywheels proved far more difficult than expected. So difficult, in fact, that the largest commercial units constructed to date are 400 times smaller than those Dr. Post envisioned-in spite of a critical need and a huge potential market. But recently LaunchPoint Technologies discovered a new type of magnetic bearing and flywheel structure that will finally permit the construction of utility-scale flywheel electricity storage systems. We call these units Power Rings.

In previous work funded by grants from the Navy, the New York State Energy Research and Development Authority, the National Science Foundation, and the Office of the Secretary of Defense we developed design methodologies, optimization algorithms and a preliminary Power Ring design. In this project, our goal was to create the detailed design of a small scale Power Ring, fabricate and assemble the ring, integrate the suspension system and rim with motor technology developed in an NSF grant, and test the ring at gradually increasing performance levels to the maximum speed consistent with safety. We successfully achieved most of these objectives. A 20-inch diameter carbon fiber composite rim was fabricated, along with all of the other properly-scaled components required for an operational Power Ring. Subsystems were individually tested when possible, and assembled into a complete system including the motor/generator. A control system was designed and assembled, including laser sensors to measure rim position deviations from equilibrium, a digital processor to compute correction signals, power amplifiers and control coils to magnetically correct rim position. System tests were begun, rim levitation was achieved, and low speed motor operation was demonstrated.

During the course of this grant the national energy situation degraded far more rapidly than almost anyone expected. Oil prices went from \$50/barrel in 2005 to \$134/barrel at the time of this writing. Coal and gas prices climbed as well, and along with concern about global warming greatly increased interest in renewable energy and energy efficiency. Energy organizations and officials finally began to understand the need for energy storage. These factors, and the substantial technical progress we were able to achieve as a direct result of this grant from the DOE and previous grants from other government entities, enabled us to attract commercial venture funding to continue development and test of Power Ring technology. As of this date, we are continuing tests and refinements of the small scale ring. We are also analyzing design alternatives for a much larger ring suitable for commercial applications, and beginning its design. That Power Ring, and its derivatives, will have major beneficial consequences for US users of electric power. 


\section{Project Description}

\section{Original Project Goals and Objectives}

Our objective was to demonstrate stable levitation of a small scale Power Ring spinning at the highest speed safely attainable with limited facilities. Specifically, our goals were to:

- Analyze and model rotor dynamics;

- Design a subscale Power Ring using a carbon fiber rim supplied by Dr. Charles Bakis at Pennsylvania State University;

- Fabricate and assemble the Power Ring;

- Integrate the suspension system and rim developed in this grant with motor technology developed in an NSF SBIR grant.

- Execute a series of tests at gradually increasing performance levels to the maximum speed consistent with safety.

These direct project objectives supported a longer term effort to secure the development and commercialization funding that will eventually lead to large scale (multi-megawatt, 1000 kg+) Power Ring products for power quality and grid reliability/stability applications.

\section{Variance From Original Goals and Objectives}

All of the original goals and objectives were achieved, with the exception of testing at increased performance levels. We analyzed and modeled the rotor dynamics and the results showed that our design does not have structural resonance problems. We designed and fabricated a prototype small scale Power Ring unit with a carbon fiber rim, magnetic suspension and active control system. The prototype is integrated with the motor previously developed under the NSF SBIR grant. We successfully levitated the rim on the magnetic suspension system and used the motor to rotate the rim.

The grant funding was insufficient to achieve all of these goals, but we were successful in raising outside venture funding, which has allowed our research and development program to continue.

As of the writing of this report we have not achieved the high bandwidth levitation required for higher speed motor testing. This is due to sensor performance problems that we have characterized and are in the process of resolving. Thus while we achieved levitation and rotation with the motor, we have not yet not fully achieved the stated objective of rotating the rim at the maximum speed consistent with safety. We plan to achieve this goal within the next 2 to 3 months as we continue our development using venture funds.

\section{Work Performed}

Control System Design: Actual-100\% complete. Block diagrams for the electrical and controls systems have been developed. The control and DAQ computer is assembled and set up.

We have developed simplified PID controllers for initial levitation that is robust to plant variations from prediction. Sensor have been switched from analog mode to digital mode and drivers created for 
the control system computer. In the future the sensors will be replaced with different models that have less delay.

Simplified prototype motor drive and controller is operational and tested.

CAD Layout: Actual-100\% complete.

CAD Details: Actual-100\% complete.

Safety Shield Design: Actual-100\% complete.

Fabrication of the safety shield has been postponed until the additional funding comes in to support the fabrication and follow on high speed testing.

Prototype Fabrication: Actual-105\% complete.

Training wheels completed, and a new design of training wheels that will allow a "rotor drop" (i.e. levitation failure) with the rim moving faster due to motor operation is designed and presently being fabricated. New mounts for the new faster sensors are also being fabricated.

Prototype Assembly: Actual-100\% complete.

Sensors and control system are wired and the control rack is assembled.

Testing: Actual-100\% complete.

Flexible modes and damping in the rim have been experimentally determined. Levitation and rotation with the motor have been successfully achieved. 


\section{Task 1a. Preliminary Study-- Develop Operation Specs}

Operational requirements have been defined. For this initial demonstration model, we determined that one of the key requirements is that the design minimizes custom tooling and setups from the various component and material vendors in order to keep the fabrication costs within the budget. Thus, our operational requirements were loosely defined to allow the specific technical requirements to bend to match the available materials and components.

\section{Task 1b. Preliminary Study--Rotordynamics Analysis}

We developed analytical expressions for the rigid body dynamics and approximations for the flexible rotor dynamics, and applied them to a subscale ring model approximately the size of our expected design. These analyses did not indicate that there will be any rotordynamic resonance issues. We also studied the damped rotordynamic phenomena that may occur. We know from previous research that structural damping within the materials on the ring can excite instability -indeed, one of the goals of this project was to measure the resulting damping in our ring structure once it was assembled. However, the exact mechanism by which the damping can cause problems was not initially known. Our studies produced a mathematical formulation of the rotating versus non-rotating damping effects on the ring flexible mode dynamics.

We planned to use a low-cost rotordynamic finite-element analysis (FEA) package published by a university in Italy for the damped rotordynamic analysis. However, detailed examination of the mathematical formulation used by the package showed that it could not provide the results we required. We then surveyed a number of commercial rotordynamic packages, and found few capable of the necessary analysis. Most packages are intended for analysis of long, skinny flexible rotors (turbines, pumps, motors) and thus make mathematical assumptions that would invalidate their results for our structure (thin-walled, low profile hollow ring). We did find that the Ansys Multiphysics package could do the analysis required, and elected to license that software.

Since damped rotordynamic models depend on the damping properties of the materials and assembly, which we could only roughly approximate prior to building our first unit, our strategy was to build the ring first and measure its actual damping properties. We then used the resulting data with Ansys to perform the rotordynamic FEA.

We realized additional need to understand the flexible ring dynamics with regard to the motor design for our concurrent NSF flywheel motor grant. We developed analytical models of the flexible modes that allowed us to understand that the gyroscopic effects will not have a large effect on the flexible mode frequencies in our operational range. This understanding allowed us to do a mechanical FEA solution using available FEA codes that do not include the gyroscopic coupling. We compared the FEA results for the flexible rim modes with analytical approximations that include the gyroscopic coupling. The results all ended up within a $+/-25 \%$ range of each other. At worst case, the lowest flexible mode always remains safely above the maximum spin frequency of approximately $350 \mathrm{~Hz}$. 
Model name: comp cyl 1

Study name: 07 T700 solid w mags

Plot type: Frequency Displacement7

Mode Shape : 7 Value $=\quad 708.98 \mathrm{~Hz}$

Deformation scale: 0.23322

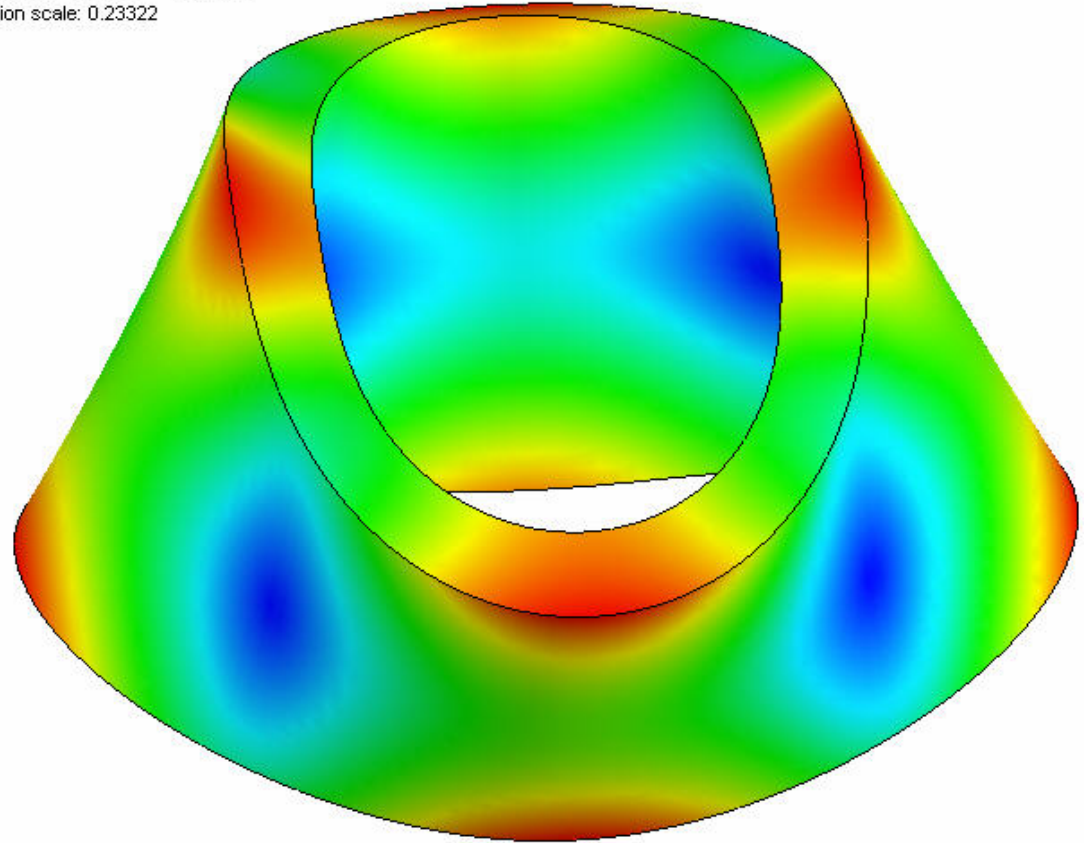

Figure 1. Rim Dynamics Analysis _-- Lowest frequency flexible mode of rim

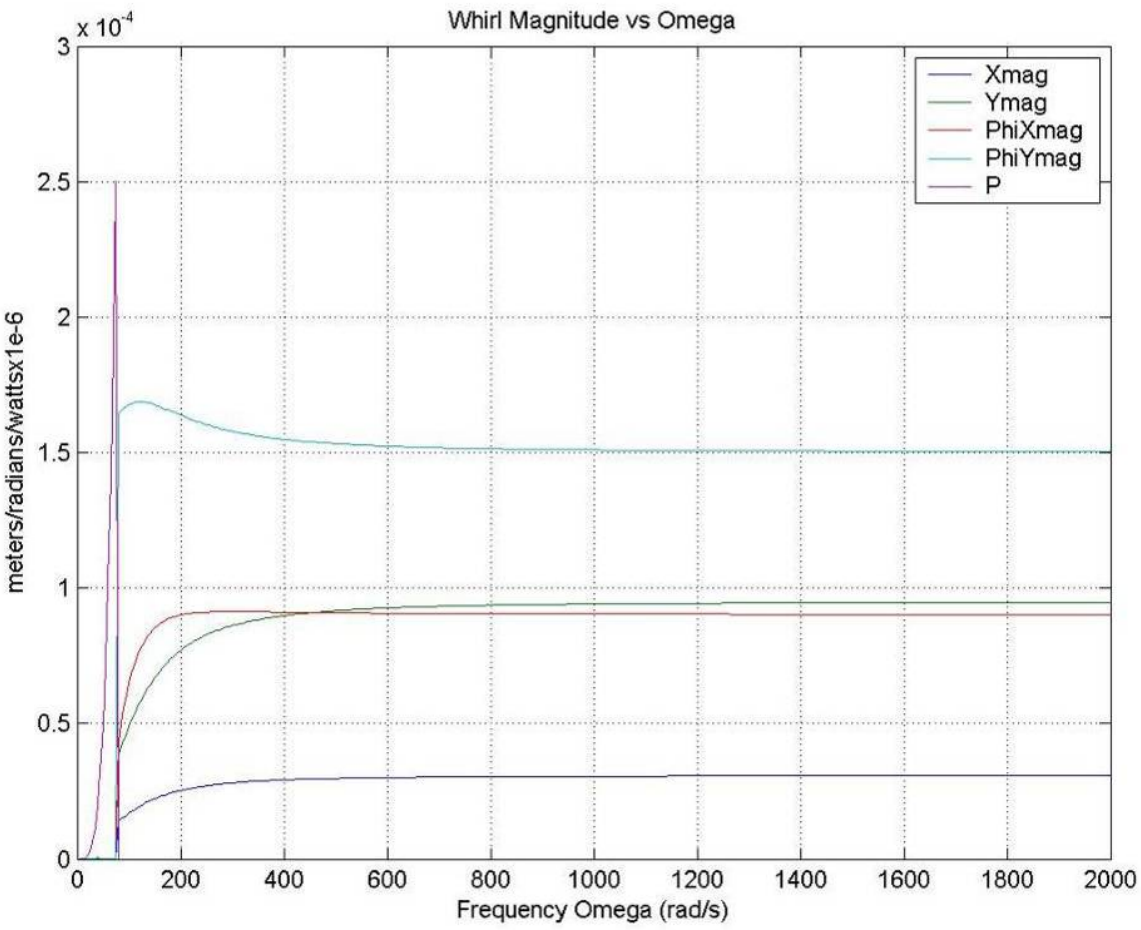

Figure 2. Predicted Imbalance Response/Whirl Magnitude vs Frequency 


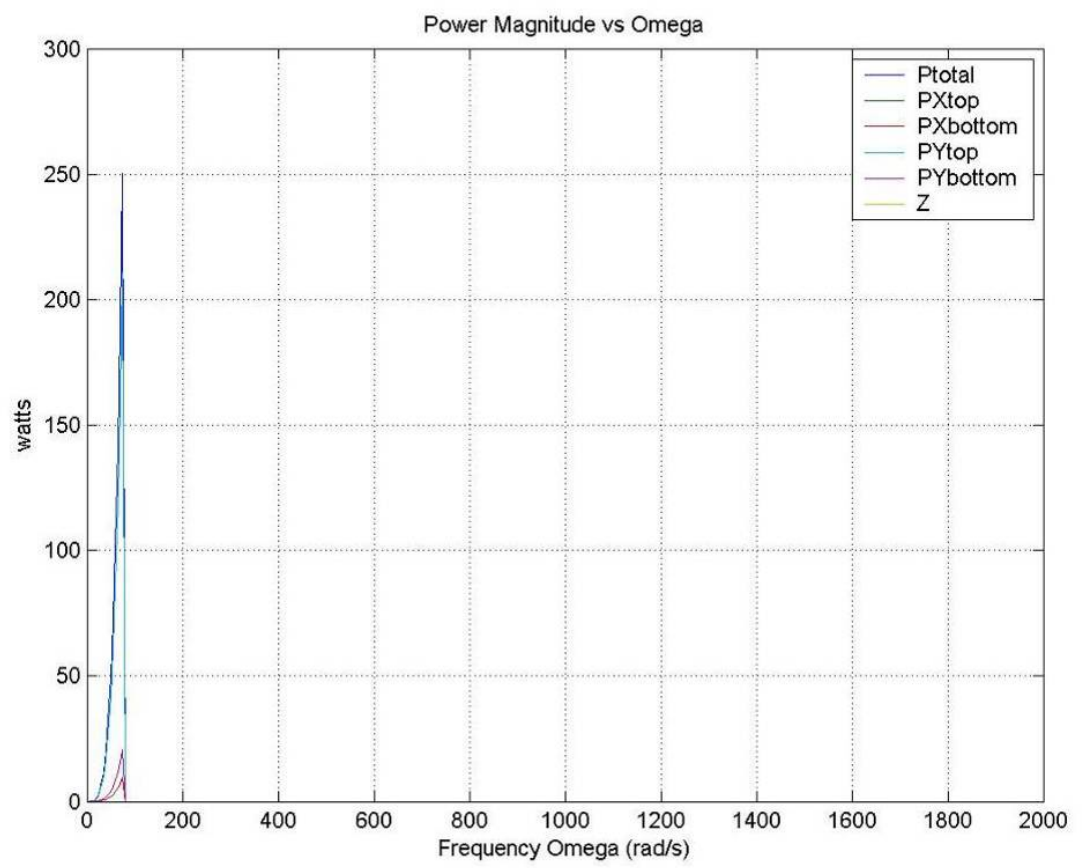

Figure 3. Predicted Imbalance Response -- Actuator Power vs Frequency. Power increases rapidly until the system passes through the suspension critical frequency. In supercritical operation a notch filter can be employed to reduce the response to rim imbalance and the actuator power drops to very low levels.

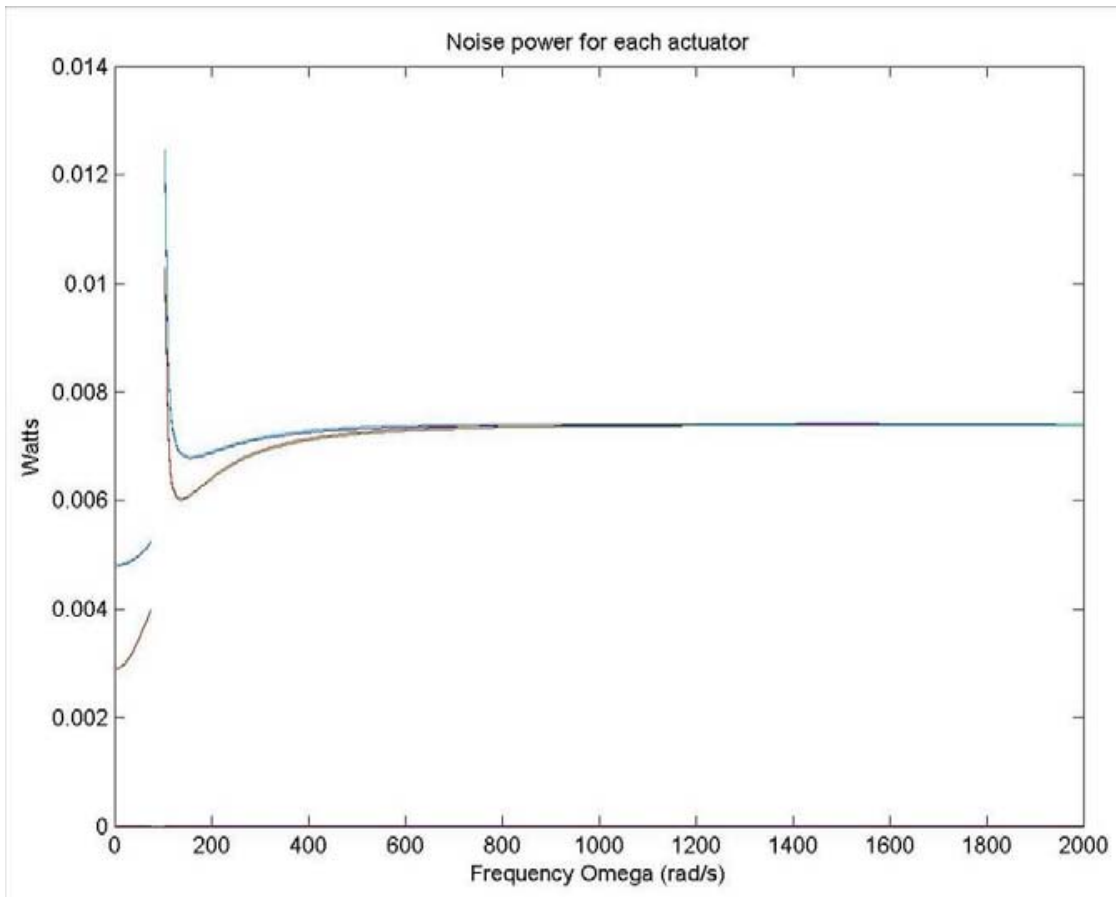

Figure 4. Predicted Actuator Power from Sensor Noise vs Frequency 


\section{Task 2a. Sub Scale Test Unit Design--Spec, Size Ring}

The ring sizing, levitation design, and actuator design tasks turned out to be constrained more by vendor capabilities and tooling rather than equations and ideal sizes. We researched vendor capabilities and analyzed the achievable performance with readily available materials sizes and standard tooling. For cost reasons, it was necessary for us to use whichever available components could provide the most useful demonstration of our technology, rather than commissioning more expensive custom components. We determined the available ring winding mandrels and selected a ring inside diameter based on a mandrel available at Toray Composites America, our preferred vendor. Unfortunately, partway into the project, Toray decided to leave the flywheel rim manufacturing business. We were forced to begin a search for a substitute vendor.

We selected a new vendor for our carbon fiber rim. Dr. Charles Bakis of Pennsylvania State University has manufactured flywheel rims for research projects for many years, and agreed to have a summer school student manufacture the rim that we require. Part of our objective to maintain low cost was to select a ring size that matched tooling already available from the ring vendor. We researched the capabilities of the tooling at Penn State's fabrication facility and designed a carbon fiber rim that fit within the capabilities of the University facilities and the project budget.

As another cost-saving measure the rim was fabricated by a summer school student. This delayed the rim fabrication until the end of the summer, but not represent a delay to our original fabrication schedule.

\section{Task 2b. Sub Scale Test Unit Design--Levitation Design}

We researched magnet vendors and determined initial sizing and magnet materials properties, then proceeded to analyze the suspension designs that we could build using the available sizes. A determination of the achievable suspension performance was needed to select the ring thickness (and weight). We built parametric FEA models of the suspension design to utilize to verify the results of our analytical design methods.

We procured samples of the new magnet material and built test articles with it. (See Prototype Fabrication below).

We created an analytical Mathcad suspension design sheet that could be used to quickly optimize the suspension design. Designs from the Mathcad sheet (Figure 5) show a bearing .125 ” thick ( $\sim 3 \mathrm{~mm})$ and .625 ” wide on the ring, and .25” thick ( $6 \mathrm{~mm})$ and .625 ” wide on the stator. Two bearings would be required to support a $100 \mathrm{~kg}, 20$ ” ID ring with a .125” levitation gap. We verified the analytical sheet predictions with our parametric FEA models and with measurements from test articles we fabricated.

We tested the prototype magnet arrays fabricated with the new magnet material. (See Prototype Fabrication below).

We completed a point design for the system. System modeling and analysis was performed to optimize the design and ensure that all subsytems can meet the requirements imposed upon them by the system design.

Our analysis of the bearing levitation forces coupling into the rim rotor dynamics led us to change the proposed locations of the bearings from the ends of the rim to a more centrally 
located area. This change increases the stability of the "tilting" mode of the rim and decreases required actuator work and power to stabilize the rim.

We performed further analysis to study the relationships between the suspension characteristics, the control system, and the rim dynamics to determine if further optimization of the suspension design would reduce overall suspension system power. Detailed analysis of the predicted "magnetic roughness" of the bearing and the coupling of the resulting "suspension noise" into the system dynamics was also performed.

We completed design of the PM bearings for the suspension system. Analysis of the system dynamics, gyroscopic coupling, and mass imbalance and their effects on the PM bearings was completed.

2D and 3D FEA analysis runs were done to validate the analytical design worksheets. Comparisons were made with a test case experimental bearing, showing good agreement between experiment, analytical results, and FEA results.

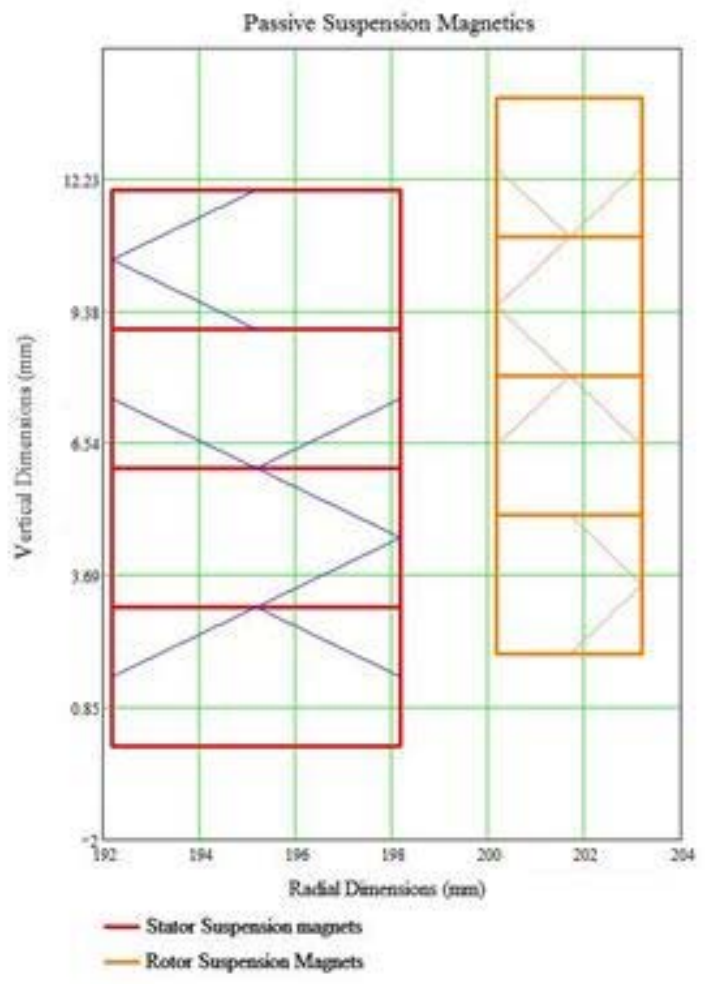

Figure 5. PM Bearing design from MathCAD design sheet 


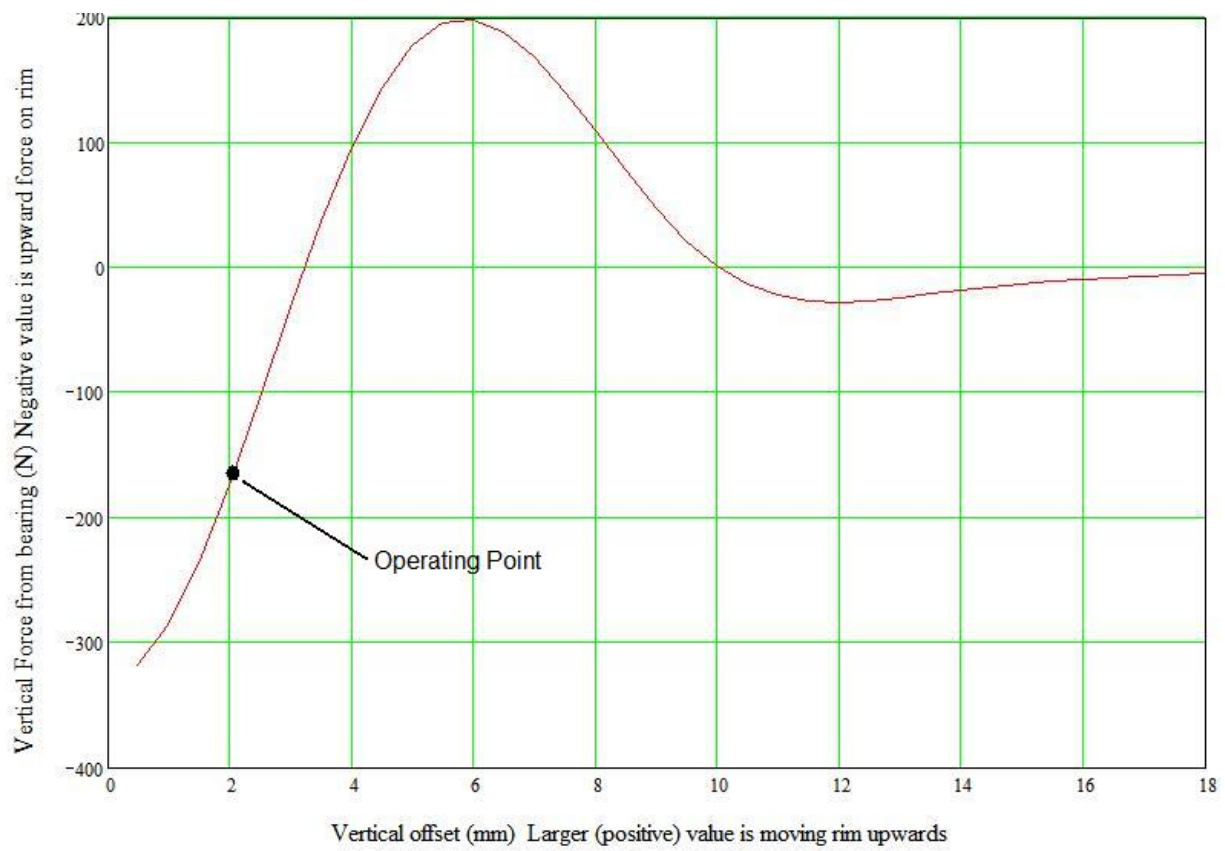

Figure 6. PM Bearing Vertical force vs vertical displacement from Mathcad model

We completed testing of the prototype magnet arrays and verified that the FEA models closely match the experimental data. See Figure 7. This gave us the confidence required to go ahead and finalize the suspension and voice coil actuator designs once the final rim dimensions were chosen.

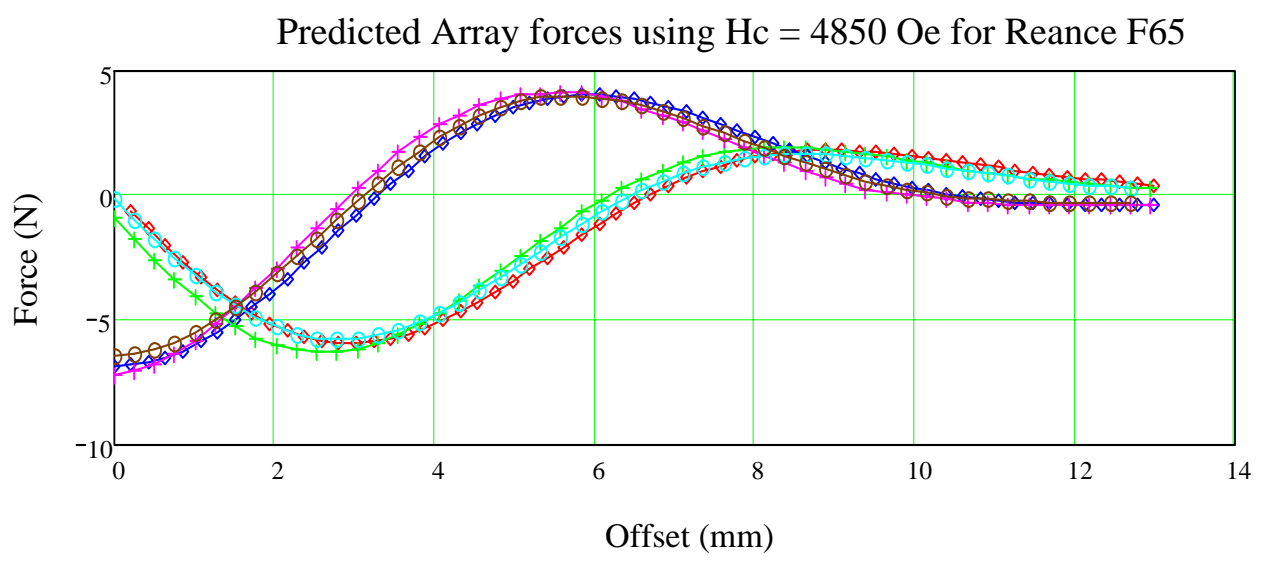

MathCad Axial Force

MathCad Radial Force

$+1+$ FEA prediction Axial

++ FEA prediction Radial

$\diamond \diamond \diamond$ Experimental Axial

ө॰ Experimental Radial

Figure 7. Comparison of analytical predictions of suspension/bearing forces with FEA results and experimental results from test segment of bearing. 


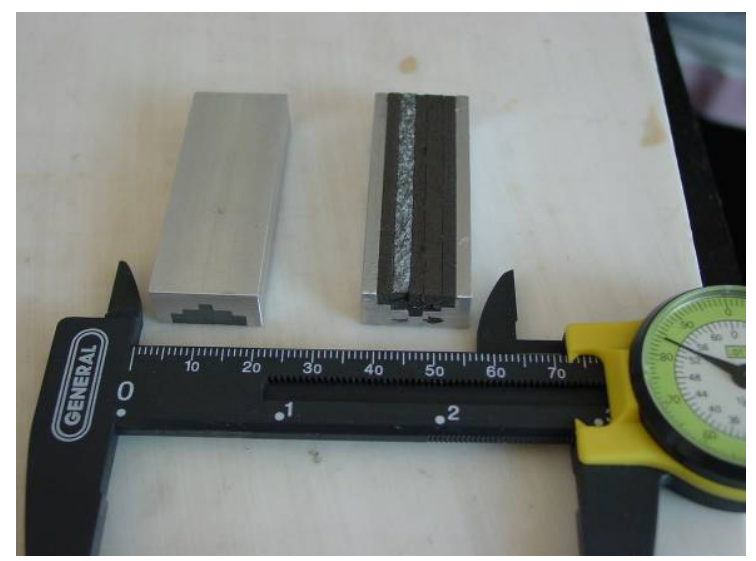

Figure 8. Test Stator Array

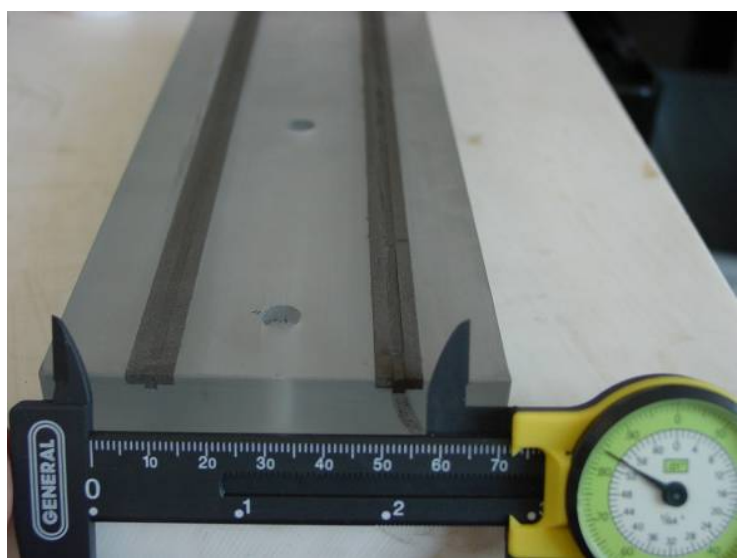

Figure 9. Test Rotor Arrays

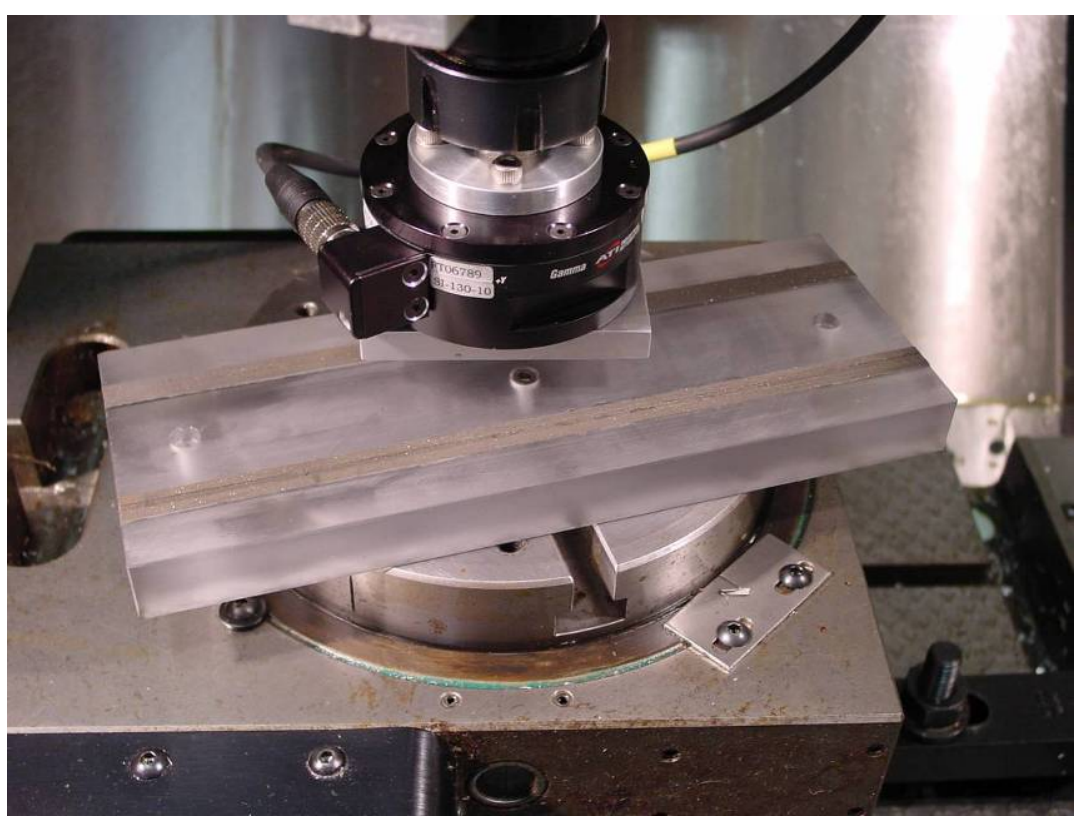

Figure 10. Magnet array force test fixture

\section{Task 2c. Sub Scale Test Unit Design--Actuator Design}

Our analytical Mathcad Voice Coil Actuator (VCA) design sheet is completed, and was used to determine the optimal design dimensionsfor the VCA. FEA models verified that the actuator has the required efficiency to achieve launch.

We verified the analytical sheet predictions with our parametric FEA models and with measurements from the test articles we fabricated.

Further system simulation of the dynamics and control system response to launch transients showed that we needed more launch power that originally expected, which required us to use larger levitation amplifiers than we had originally been planning 
A point design for the Voice Coil Actuators (VCA) was completed. Analysis of the control system and sensor noise as well as imbalance disturbance response predicted that the power losses in the VC actuators as designed would be $<250 \mathrm{~W}$ peak while spinning up, and much less when idling and storing energy at high speed.

Additional ring dynamics analysis showed that we will not be required to utilize active modal control to damp flexible modes in the ring, so the actuators do not have to be designed as "modal" actuators, only as rigid body actuators, thus simplifying the actuator and control system design.

3D FEA analysis runs were done to validate the analytical design worksheets and compared with experimental data from first article actuators.
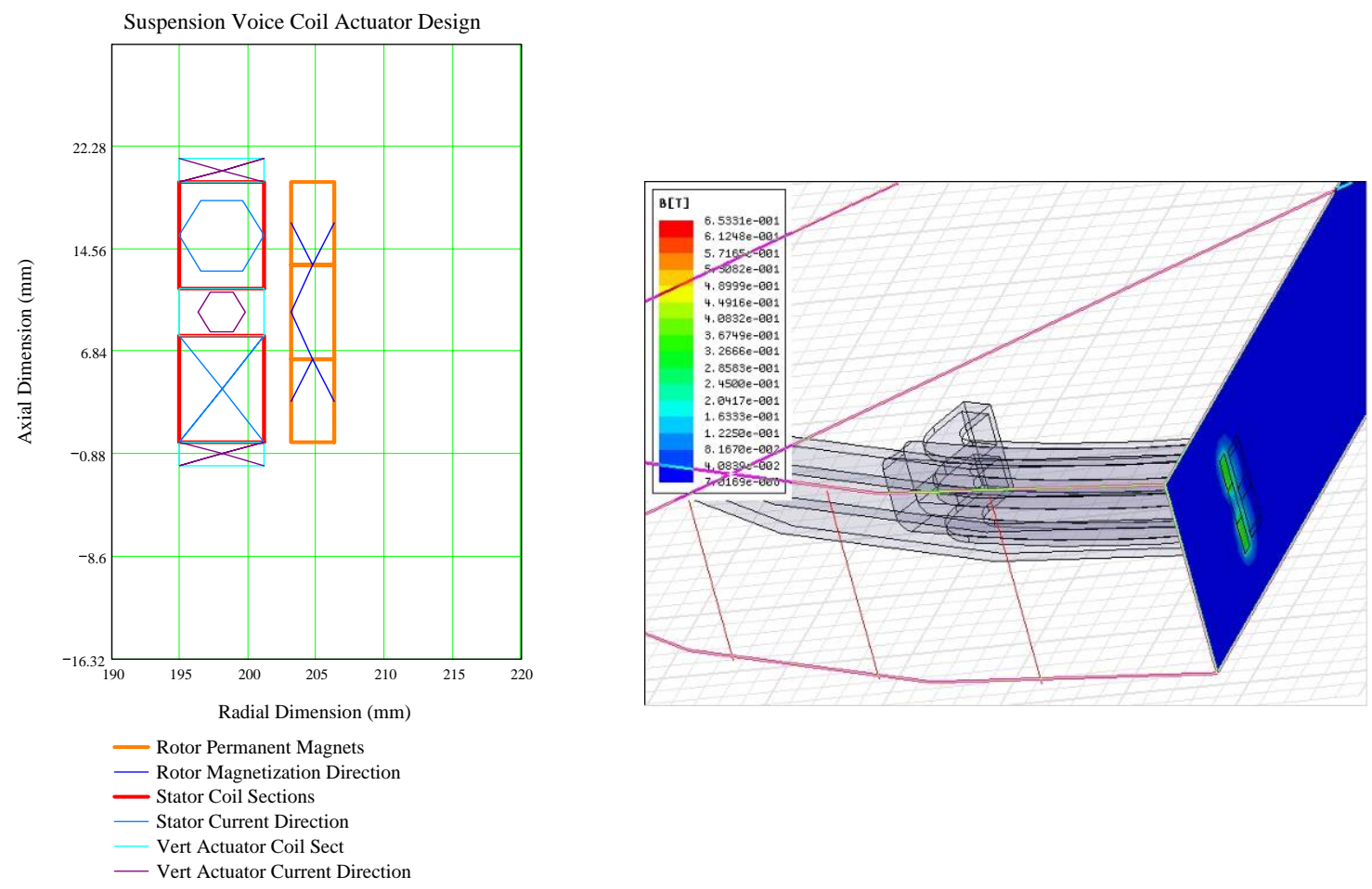

Figure 10-2: Voice Coil / Magnet design including integrated vertical damping coil.

We worked out the detailed fabrication concepts for the Voice Coil Actuator coil structures and the central support structure. See Figure 11. 


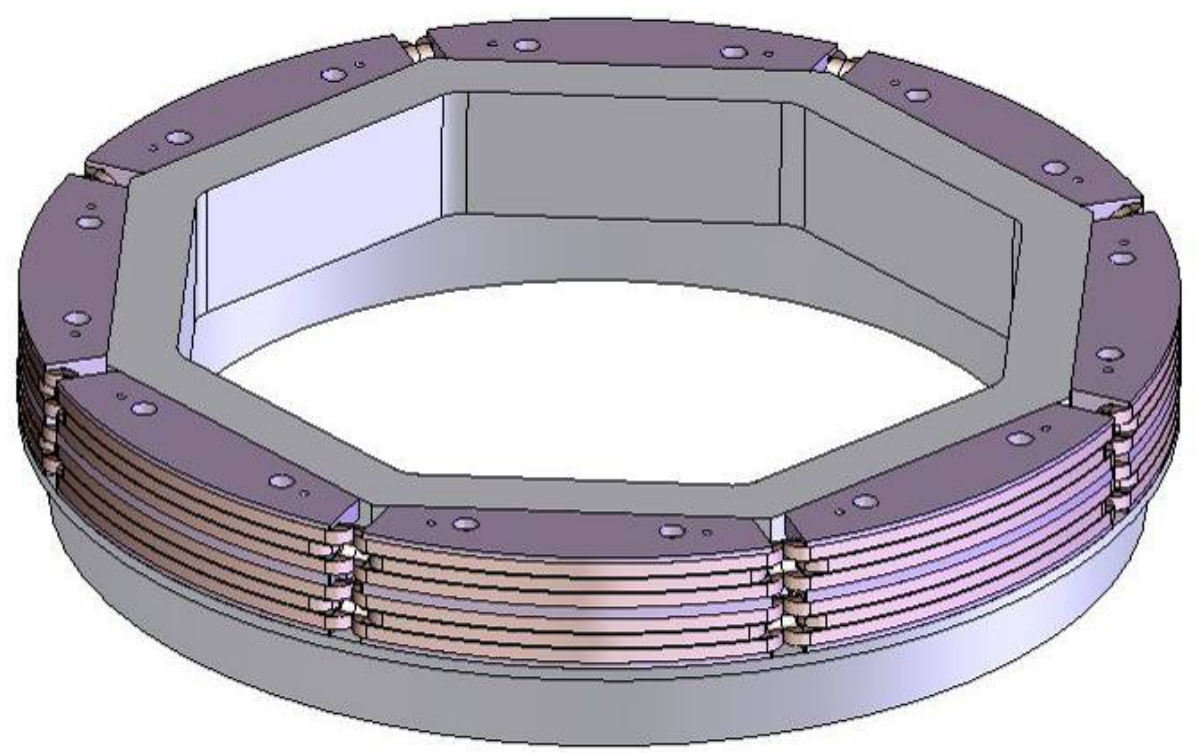

Figure 11. Voice Coil Actuator Detailed Concept

Figure 12 illustrates the detailed analysis giving the effective motor constant (Km) of the VCA when radial and axial actuators are used in combination to compensate for axial height change and VCA misalignment as rim stretches at high speed. The expected change is $1 \mathrm{~mm}$ height over entire speed range.

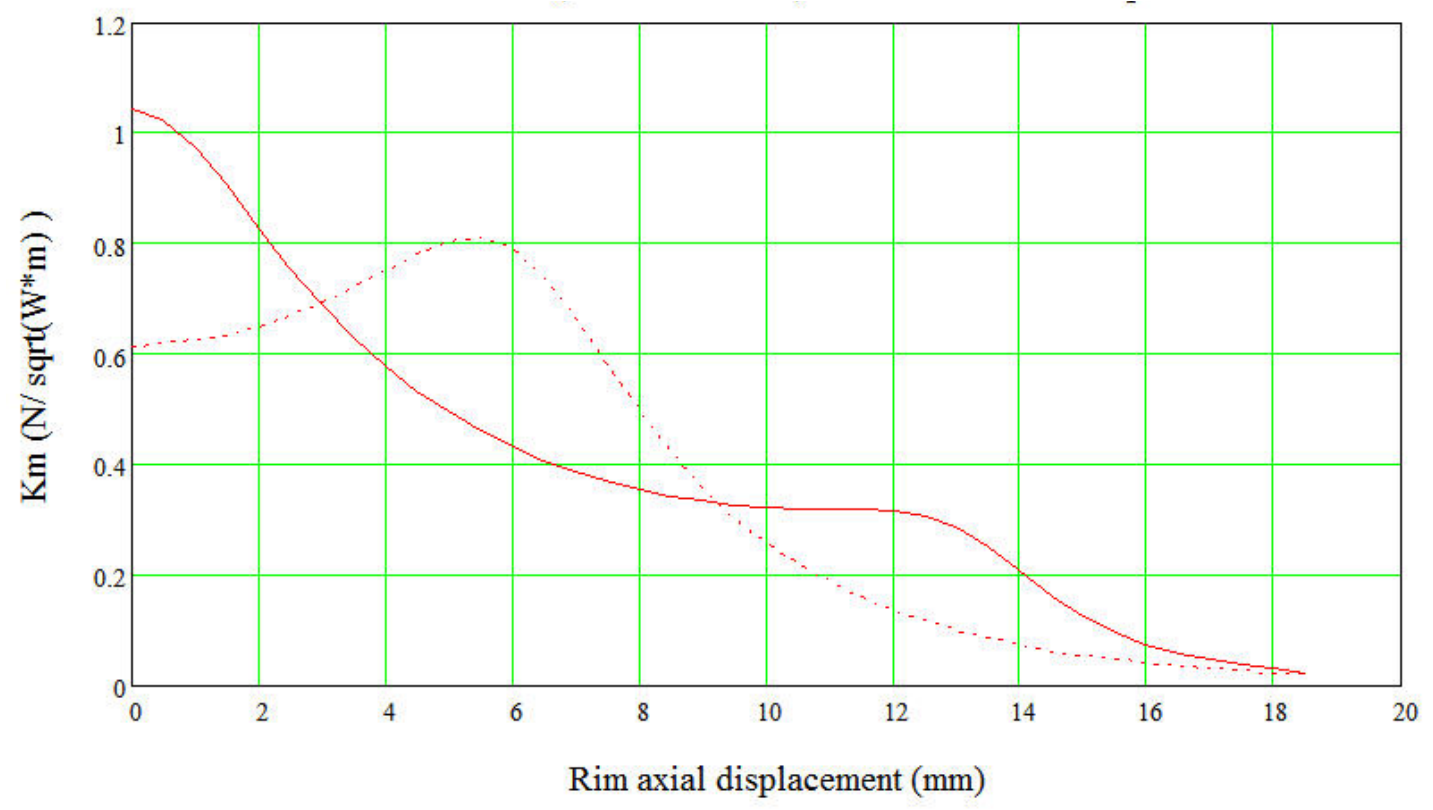

— Mixed Act Radial Km

Mixed Act Axial Km

Figure 12. Predicted Mixed actuator motor constant (Km) vs. rim axial displacement 


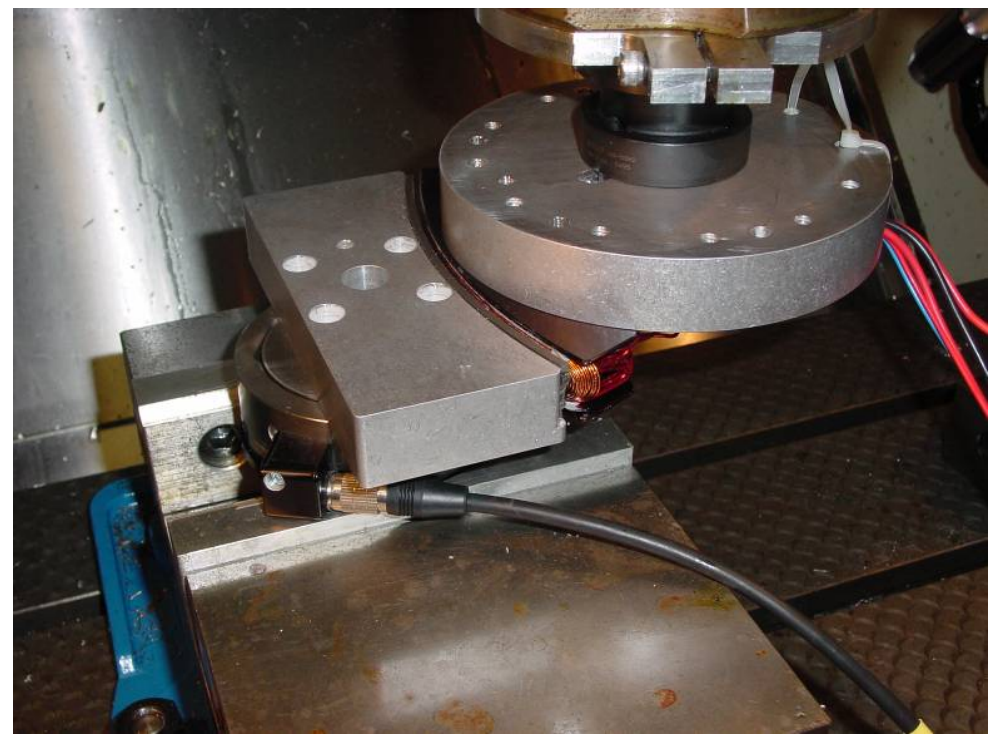

Figure 13. VCA test in progress. Coil on mandrel is mounted to mill spindle for accurate positioning, arc-segment of magnets mounted to load cell on mill table.

\section{Task 2d. Sub Scale Test Unit Design--Sensor Design}

We investigated various sensing technologies. Optical sensing was attractive and could achieve many of the technical goals, but commercial optical sensors tend to be very expensive. Eddy current/inductive sensors were more compatible with our budget, and had at least some potential to meet our accuracy/sensitivity requirements. We obtained a sample of the ring carbon fiber composite material and tested it with our in-house eddy current sensor design. The sensor did not sense the carbon fiber material, so the ring design would require a conductive coating or a conductive band added to the inside of the ring for the sensors to "look" at.

We came very close to selecting eddy current sensors as the sensing technology, but finally found an optical sensor that fit within the project budget. We were not able to purchase enough sensors to do our original planned experiment of trying to actually measure vibrational mode shapes while the rim is spinning. We could only afford enough sensors to control rigid body motions. Since our analysis showed that controlling flexible modes will not be required, this should be an acceptable reduction in control capability. We will still attempt to measure mode shapes, frequencies, and damping on the levitated (but not spinning) rim using accelerometers.

The sensors we selected have a sampling rate of $500 \mathrm{~Hz}$ and utilize a laser beam with a CCD imager and a triangulation algorithm to measure distance. The $500 \mathrm{~Hz}$ sampling rate was more then enough for the planned loop closure frequency of $20-30 \mathrm{~Hz}$ on the suspension system.

At the eventual full operational speed of the rim, the rotation frequency will be 300 to $400 \mathrm{~Hz}$, which is greater than the Nyquist frequency of the position sensor, so any geometric runout would cause an oscillating movement at a frequency greater than the sensor nyquist frequency to be presented to the sensor. We did an experiment with the sensor looking at a spinning lobed surface to determine what happens when an object is oscillating above the nyquist 
frequency in view of the sensor. We were unsure whether CCD limitations would cause the measurement to simply "blur"/average the distance, or if the sensor would alias the movement down to an apparent lower frequency. Our experiment revealed that the sensor aliased the signal down. This has implications for the eventual implementation of the control system with a notch filter for the synchronous excitation - the notch frequency might have to be moved to very low frequencies as the rim speed goes above $250 \mathrm{~Hz}$, and there may be issues of having to go through the suspension resonance a second time. This issue was unresolved in this grant as high speed testing was not part of the scope. Faster (and more expensive) sensors are available but don't fit within the budget of this project, so it may be simply a matter of spending dollars later to upgrade to faster sensors when we get funding to do high speed testing.

\section{Task 2e. Sub Scale Test Unit Design--Control System Design}

We began designing the Simulink system model for "hardware in the loop" testing of the control system. We also bega1n design work on the controller algorithm structure and investigating the stability issues involved with ring damping and sensor location.

We modeled an idealized controller and used it to predict system performance under mass/moment imbalance conditions of the rotor. Initial studies showed that a simplistic P-D controller that is unaware of the stiffness cross-coupling in the bearing will only be stable over a very limited speed range. We proceeded to model a gain-scheduled LQ optimal controller that gave very good performance for rotor imbalance disturbances. Further work remains in optimizing noise rejection of the controller, modeling real world controller limitations, and checking/improving robustness of the controller.

We completed a Matlab/Simulink model of the system dynamics (Figure 14). The model included the PM bearing cross coupling between tilt and translational forces. It also included sensor noise and imbalance disturbances into the system. A Matlab script was set up to analyze the Simulink block diagram and extract transfer functions and estimates of actuator power due to imbalance response and sensor noise.

The controller was modeled using a gain scheduled LQ controller with a Kalman filter. An additional synchronous frequency notch filter removes response from the system to the mass imbalance once the system is rotating at a supercritical speed.

The simulation suggests that the actuators will consume a peak power of approximately $250 \mathrm{~W}$ as the flywheel goes through the (unstable) resonance of the suspension system around 75 $\mathrm{rad} / \mathrm{sec}$. After passing through the resonance, the notch filter can be added in to eliminate reactions to the mass imbalance and reduce actuator power to extremely low levels, even in the presence of sensor noise.

At low speed, the notch filter cannot be used, but a feed-forward signal can be used to optimally counteract the effects of mass imbalance.

Further modeling and controls design is required to determine the effects of imperfect feed-forward and to add adaptive feed-forward that will work with real-world, noisy rotation sensor inputs and estimate unknown mass/moment imbalance.

Analysis of the vertical (passively stable) axis showed that relatively little vertical actuator power would be required to keep vertical response to bearing imperfections critically damped and keep the amplitude of the motion small. 


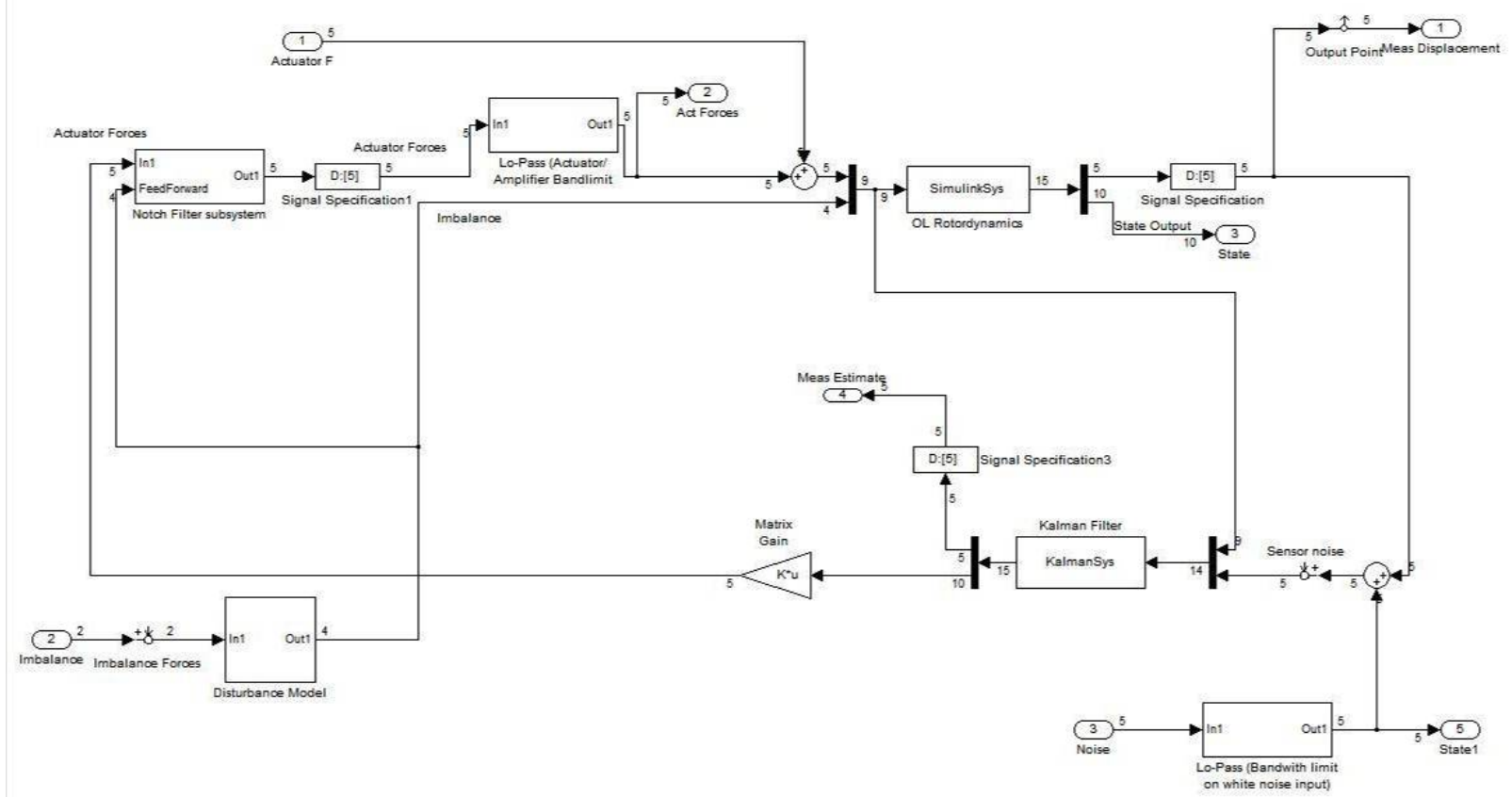

Figure 14. Simulink Dynamics and Control System Model

Further modeling and controls design is required to determine the effects of imperfect feed-forward and to add adaptive feed-forward that will work with real-world, noisy rotation sensor inputs and estimate unknown mass/moment imbalance.

Work also proceeded on developing levitation "launch" algorithms, and on getting the actual control system hardware assembled and running test algorithms. We purchased a DSP evaluation board and ran sample code on it to learn the details of implementing control systems in this particular DSP.

Controls design progressed to the detailed level of designing the specific control algorithm to be implemented on the hardware. A detailed simulation/dynamic model of the hardware was developed that would allow for testing of the control algorithm in simulation before testing on the assembled hardware. The simulation model was refined to include system non-linearities and $2^{\text {nd }}$ order coupling; and a parametric deviation study was done to assess robustness of the control algorithm.

Analysis determined the de-levitation position of the rotor and the approximate launch dynamics. Time domain simulation of the "launch" from de-levitated to levitated was performed, and results of the simulation was used to specify peak launch power requirements for the levitation amplifiers.

Progress was made on design of a notch filter control structure to prevent rotor imbalance from creating large suspension power disturbances. Virtual zero power (VZP) integrators in the control structure were also developed to allow the control system to automatically compensate for geometric and magnetic "run-out" in the bearings.

Amplifiers, energy storage capacitors and the suspension power supply were specified. The control computer was specified and ordered. Block diagrams for the electrical and controls systems were developed. The control and DAQ computer was assembled and set up.

Further analysis showed that the launch power required would be significantly higher than initially estimated, and the cost of the amplifiers required to meet the launch power 
requirements would not fit within the remaining budget on the grant. In order to test the PM bearings, we utilized a passive stabilization system using small rollers adequate for the low speed operation planned for this grant. We raised additional funding from an investor that allowed us to complete the active, non-contact magnetic stabilization system.

\section{Task 2f. Sub Scale Test Unit Design--CAD layout}

We created a parametric CAD layout that could be updated with final design dimensions as the various vendor capabilities and system analyses were completed. Detailed fabrication concepts for the central structure and the burst/vacuum containment were worked out. A detailed fabrication drawing of the carbon fiber rim was completed and delivered to the vendor.

All basic subsystems are modeled.

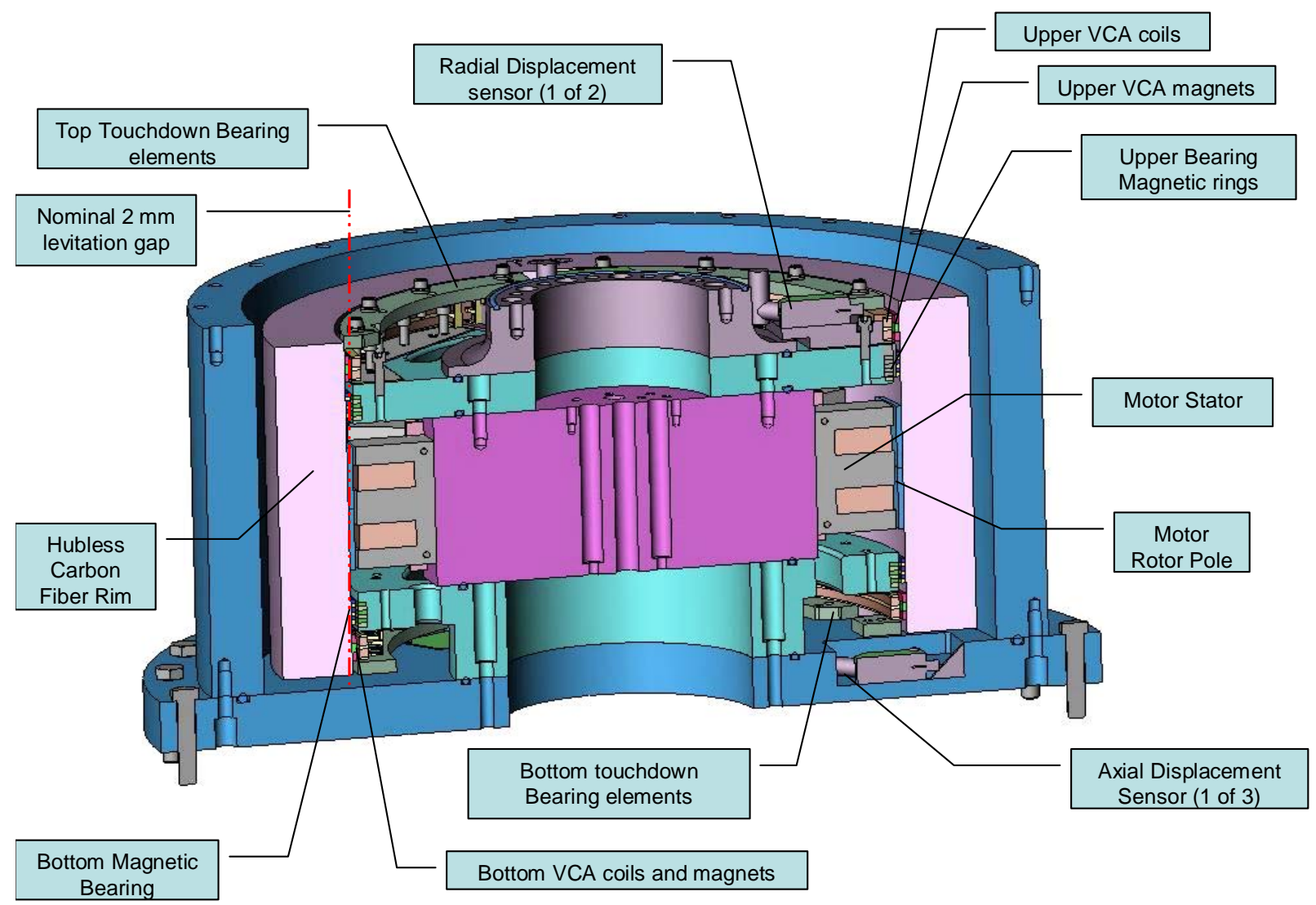

Figure 15: CAD model of sub-scale system 


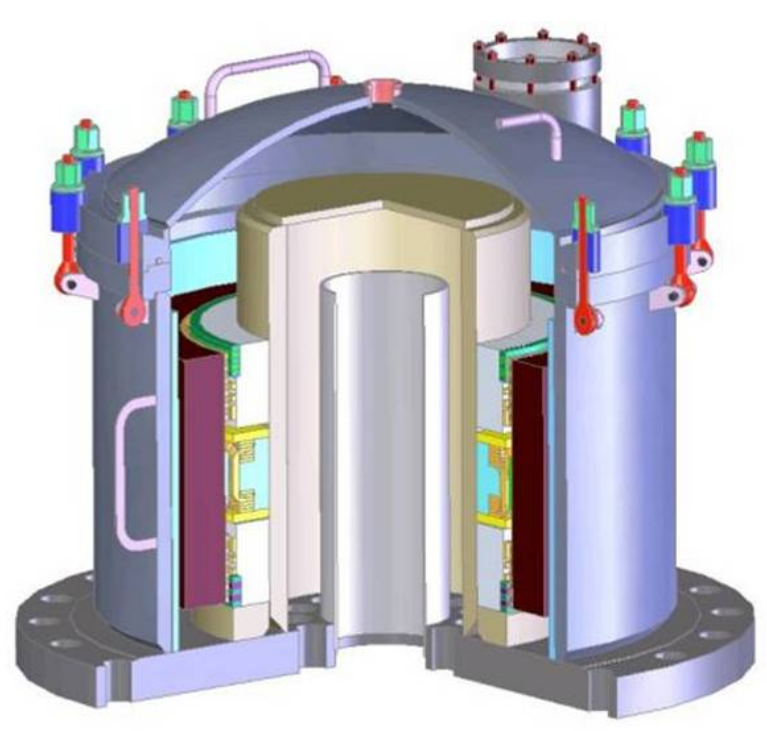

Figure 16. Cutaway View of Proposed Structure

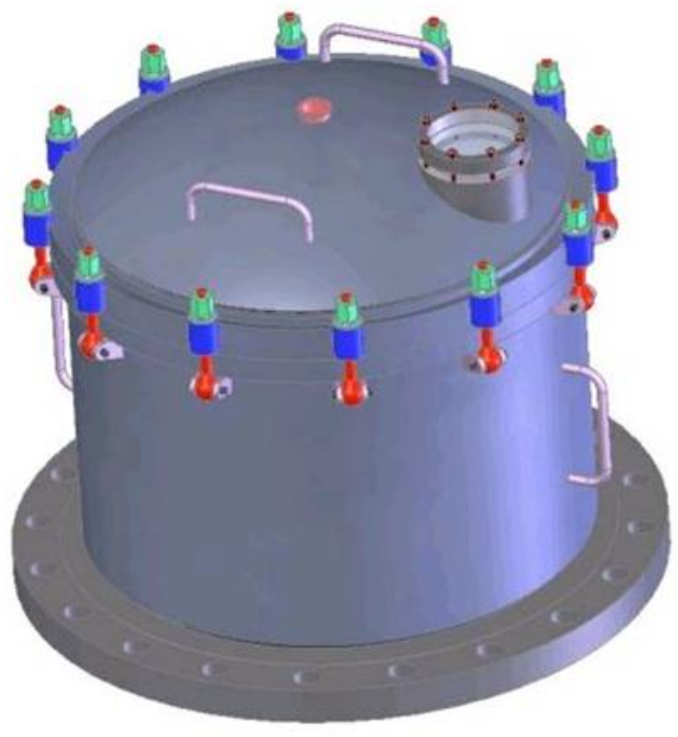

Figure 17. Proposed Containment Structure

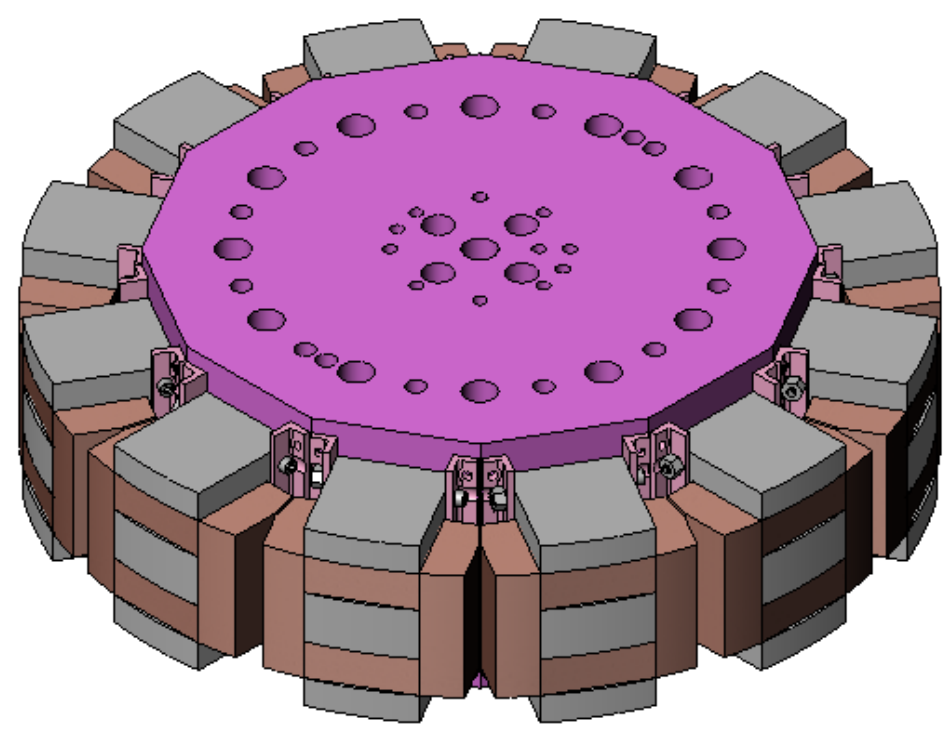

Figure 18. Detailed CAD model of motor stator

\section{Task 2g. Sub Scale Test Unit Design--CAD details}

Detailed models of various subcomponents were created. The stator structure was detailed, as well as voice coil actuators and bearing supports. Detailed fabrication drawings were completed. Design and drawings for fabrication and assembly fixtures were completed. 


\section{Task 2h. Sub Scale Test Unit Design--Safety Shield}

Conceptual design/CAD layout was completed based on a large diameter, heavy wall steel pipe and pipe flanges. A CAD detailed model was completed. Analysis work was done to estimate potential forces from a high speed rotor crash. (Although we actually never intended to run the rotor at high speed in this grant, the design will carry on to the next level of testing where high speed will be required, and so we designed for high speed/high energy testing.) Final sourcing of materials, tweaking design to match available materials, and fabrication drawings remain.

\section{Task 3. Prototype Fabrication}

We did test fabrications of magnet arrays with the new magnet material that we investigated. The test fabrication of small magnet array sections allowed us to develop and fine tune the assembly methods that were used in the demonstration ring suspension system. The assembly experience allowed us to design the demonstration wheel with the preferred assembly methods and techniques in mind. We also tested the arrays to verify that the magnet performance meets the analytical and FEA results.

The flywheel rim was filament wound and post-machined to bring it into the final ID and

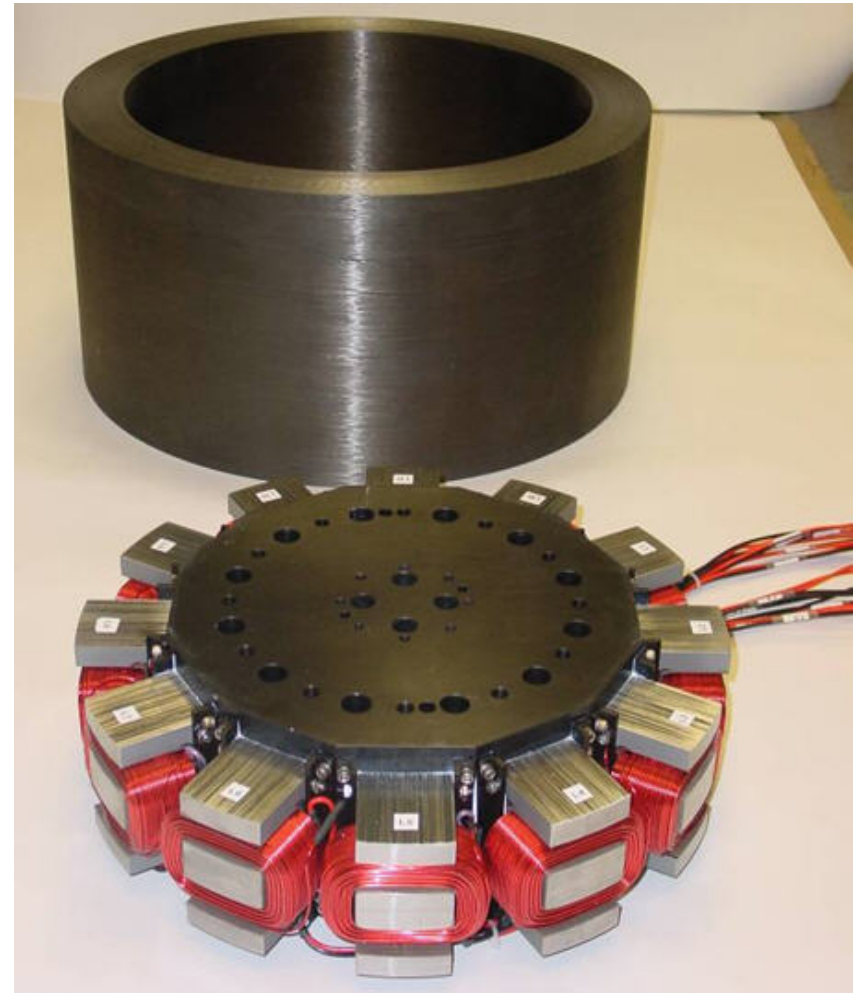

Figure 19. Fabricated motor stator and finished rim
OD dimensions.

Flywheel rim fabrication and postmachining was completed and flywheel rim was delivered. Despite designing the rim to fit on a standard 24" lathe, there was a slight overage on the rim size when fabricated, and the rim would not fit on a standard lathe. The machine shop at Pennsylvania State University chose to do post machining on a NC Mill (at no extra charge) rather than ship it out to a shop with a larger lathe.

The stator components were machined, including the base plate and Voice Coil Actuator (VCA) mandrels. The voice coils were wound. Final VCA assembly and potting was performed, as well as machining of touchdown bearing components. Magnet material for the bearings and VCA stators was received. Somaloy motor rotor pole material was received, machined into final net shape and bonded onto the rotor. All magnet assemblies were fabricated and assembled on the stator and rotor structures. 

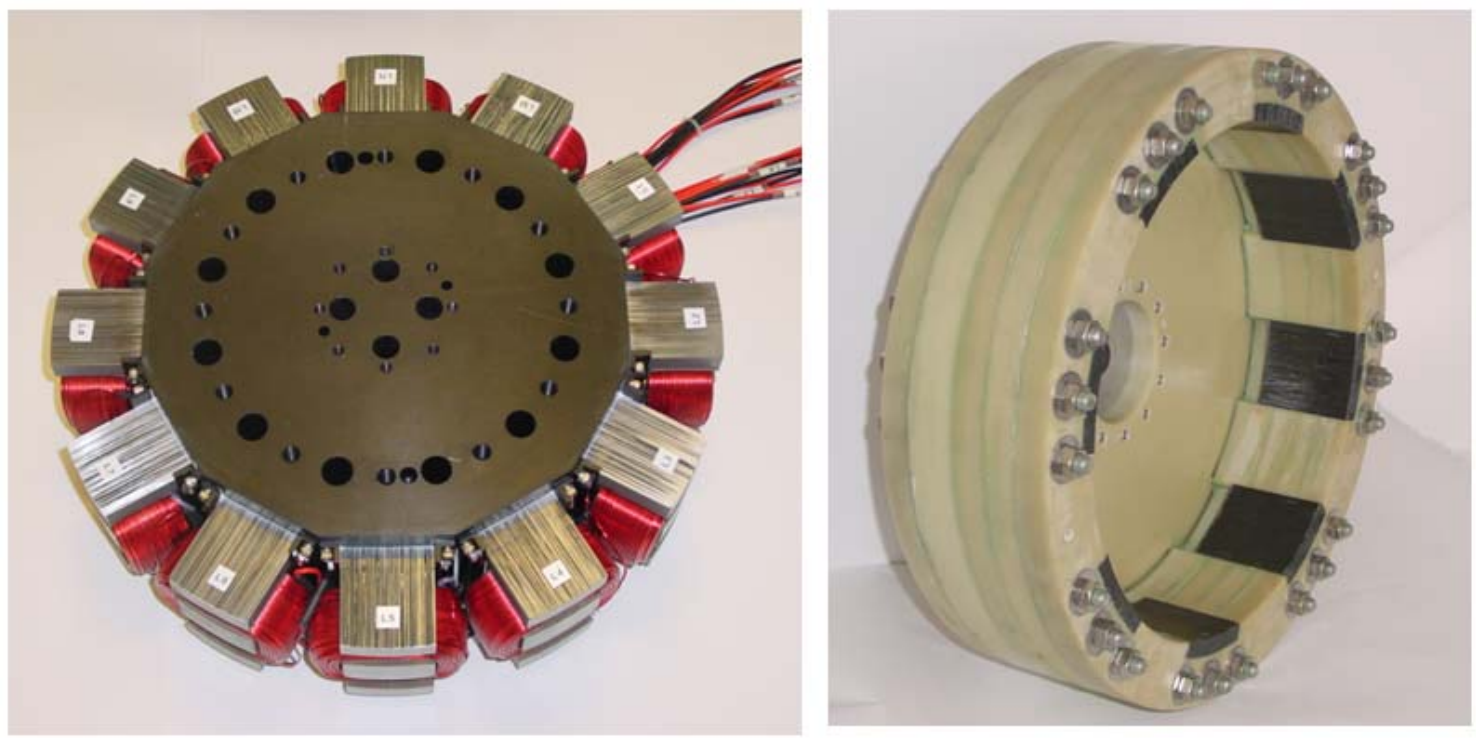

Figure 20. Motor stator and test fixture to hold rotor poles for motor characterization testing in NSF grant

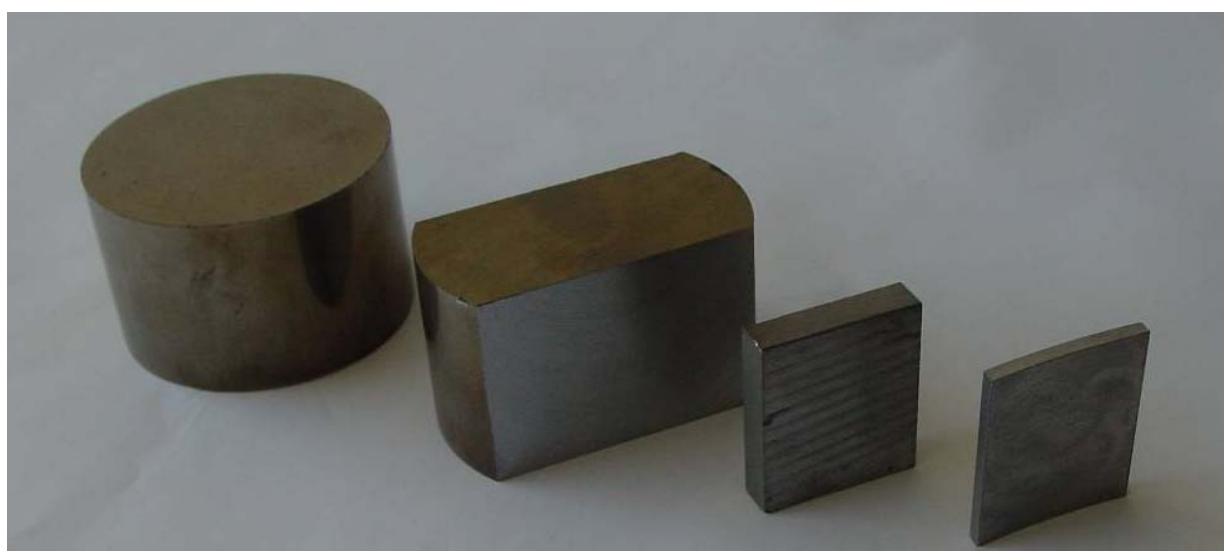

Figure 21. Somaloy motor rotor pole machining progression

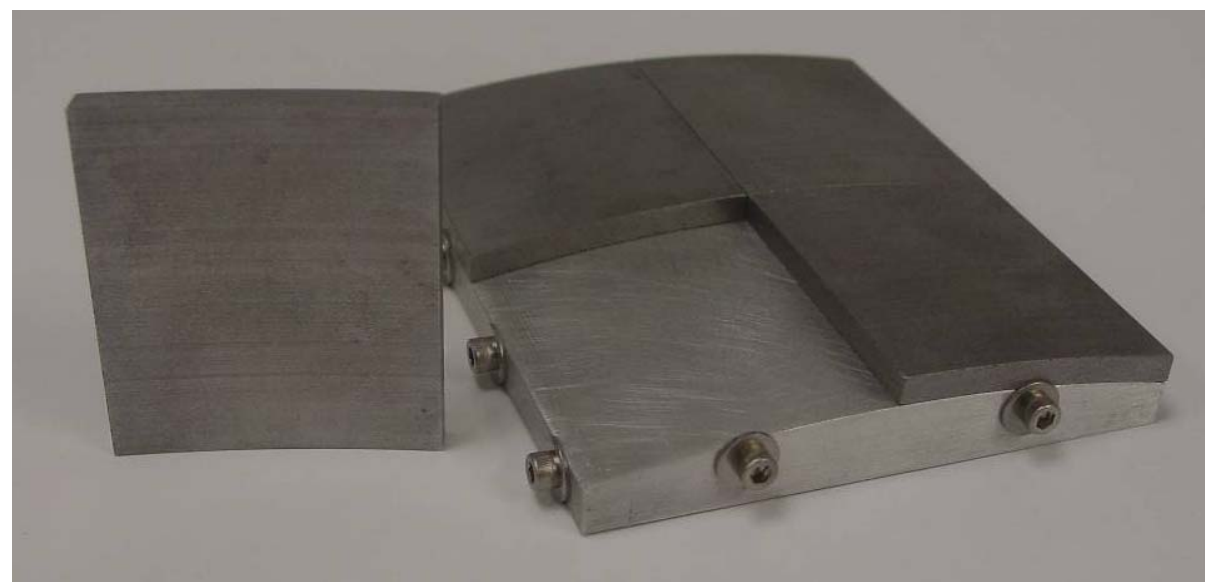

Figure 22. Motor rotor pole bonding fixture 


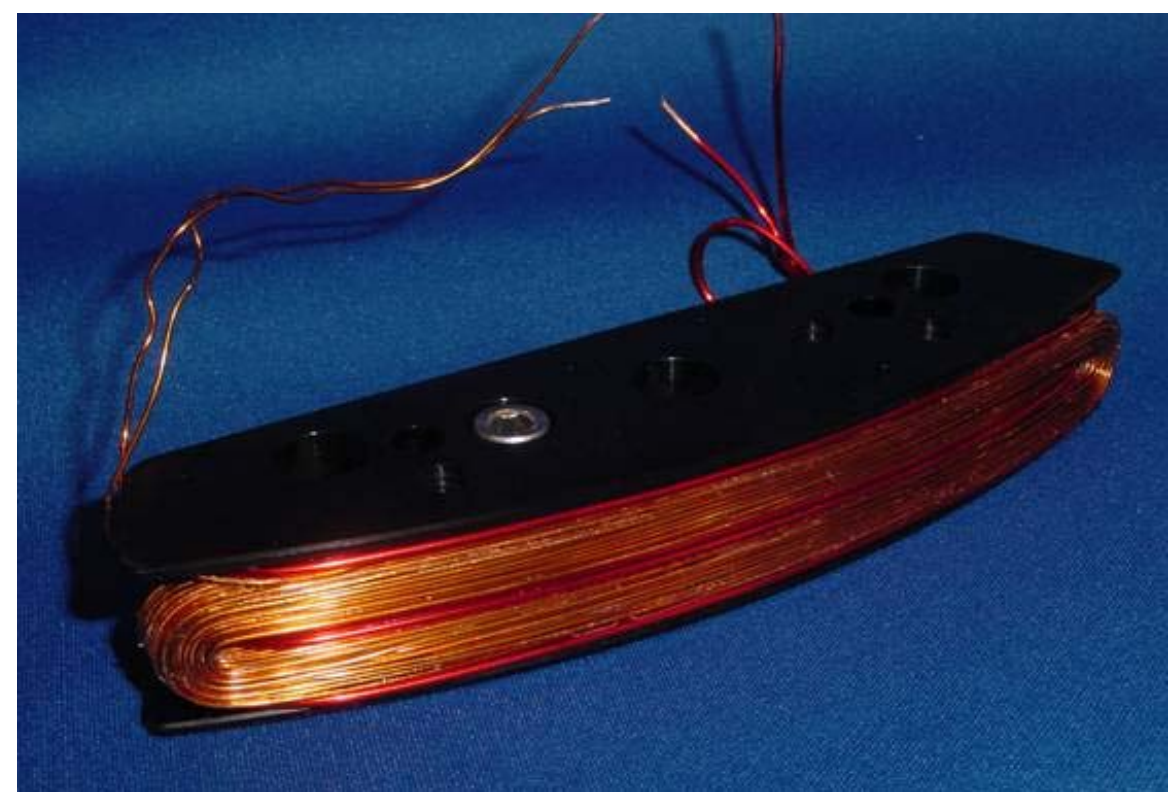

Figure 23. Finished VCA coil assembly

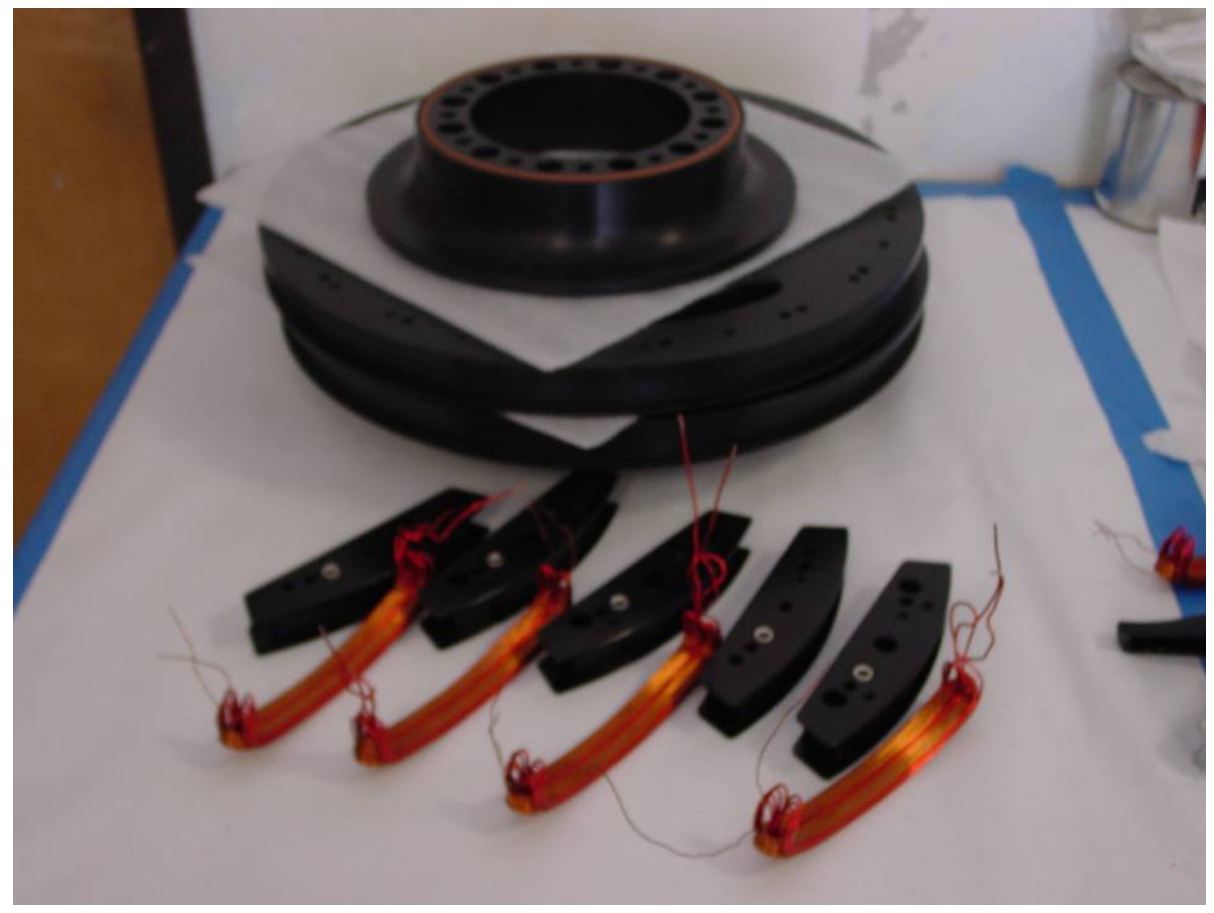

Figure 24. Bearing mounts, coil mandrels, and formed VCA coils 


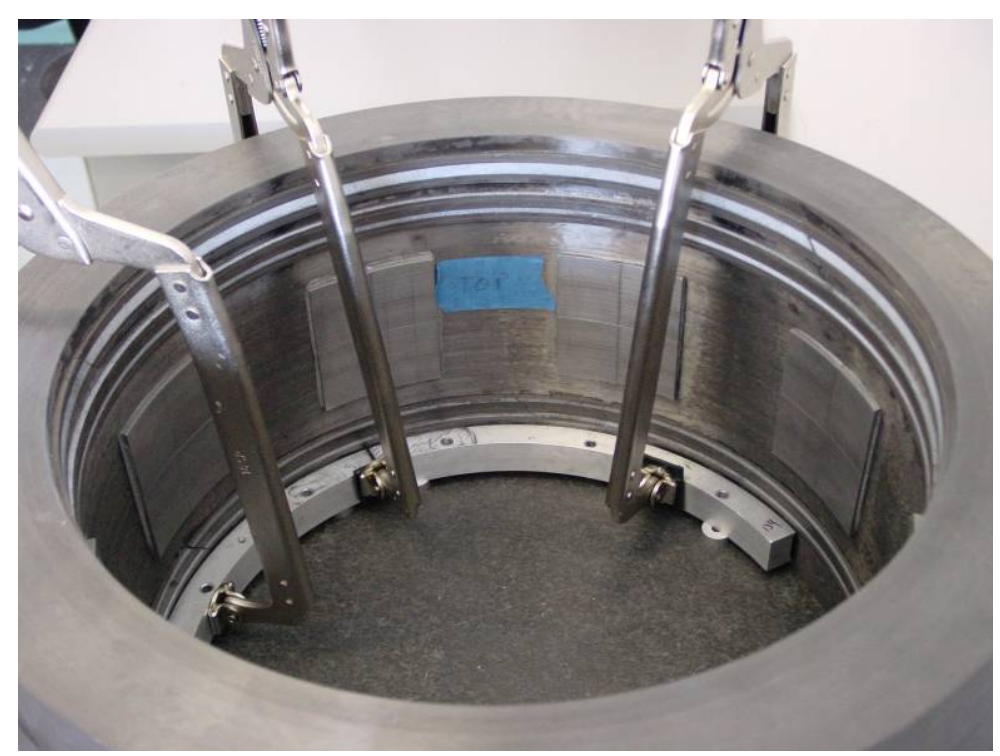

Figure 25. Magnets being bonded into rim

\section{Task 4. Prototype Assembly}

Planning and fixture design for the assembly of the magnets onto the stator and the rim, as well as fixture design for assembly motor rotor poles onto the rim was performed. Magnet assembly onto a test fixture for the VCA was performed.

All magnet assembly and bonding onto the rotor was completed. Final wiring of the motor and sensors as well as final assembly of the rotor onto the stator was competed.

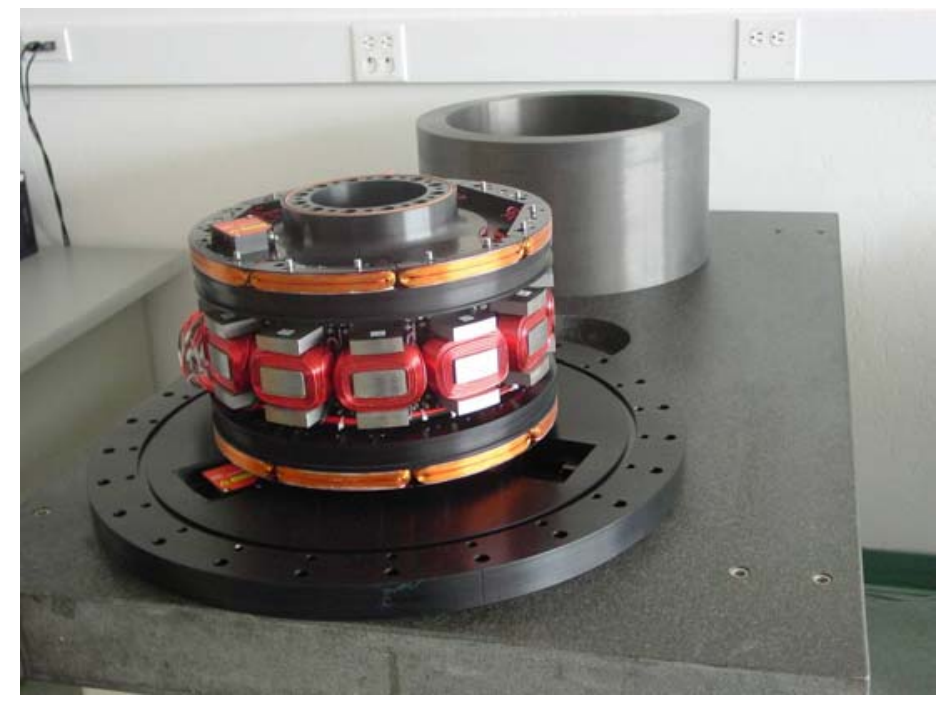

Figure 26. Assembled stator 


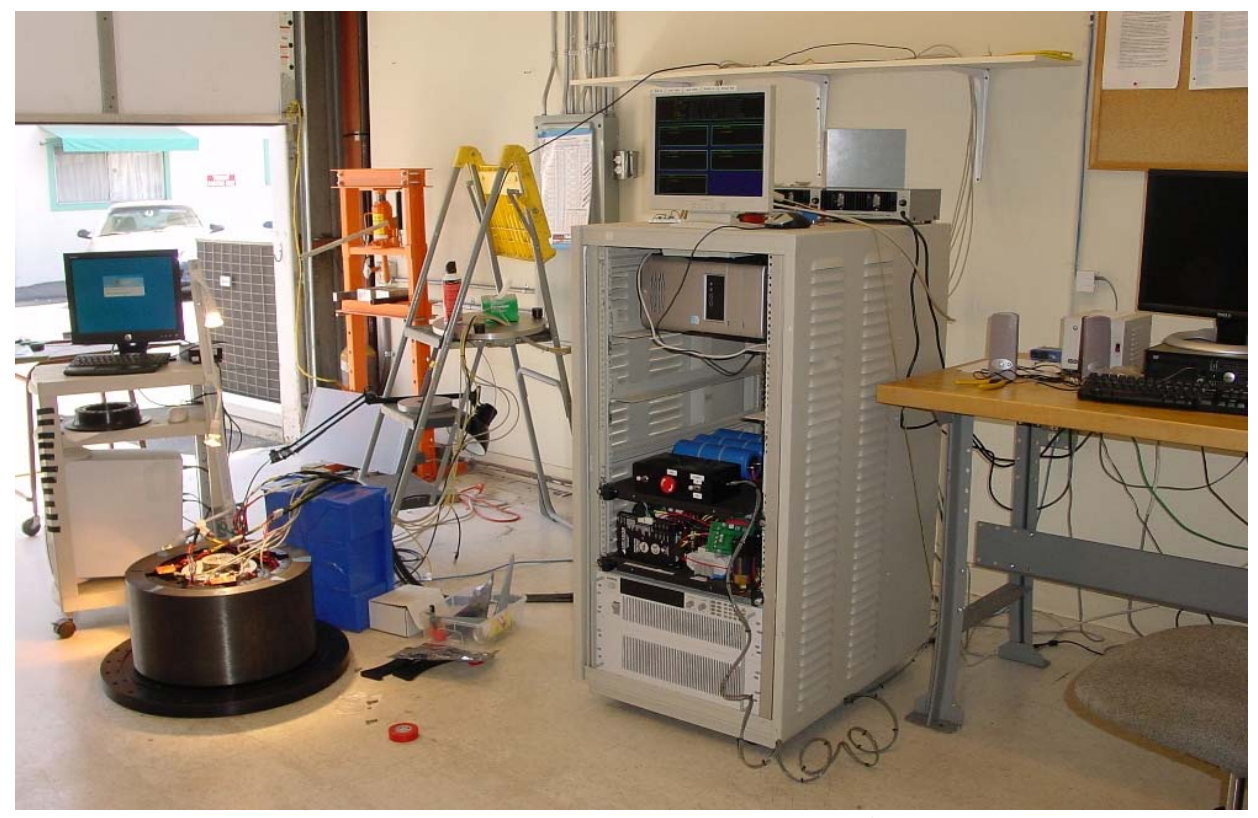

Figure 27 Demo Ring Development System

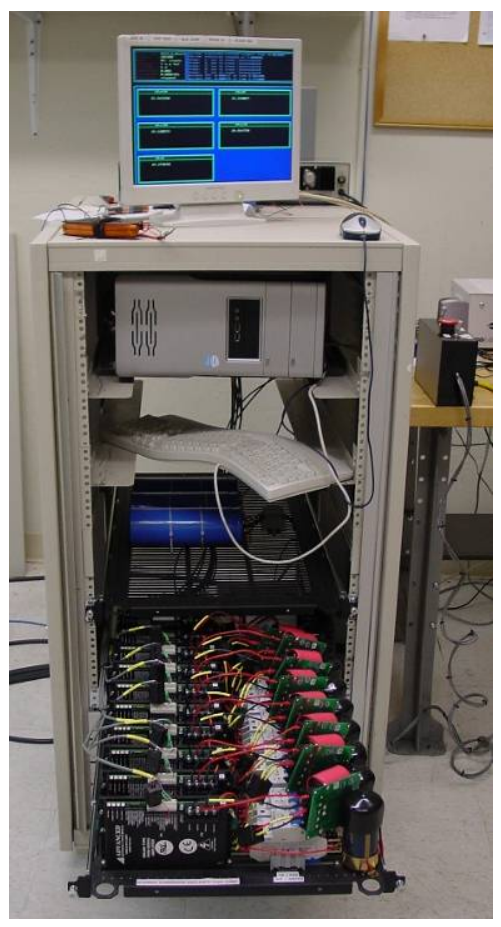

Figure 28 Control rack

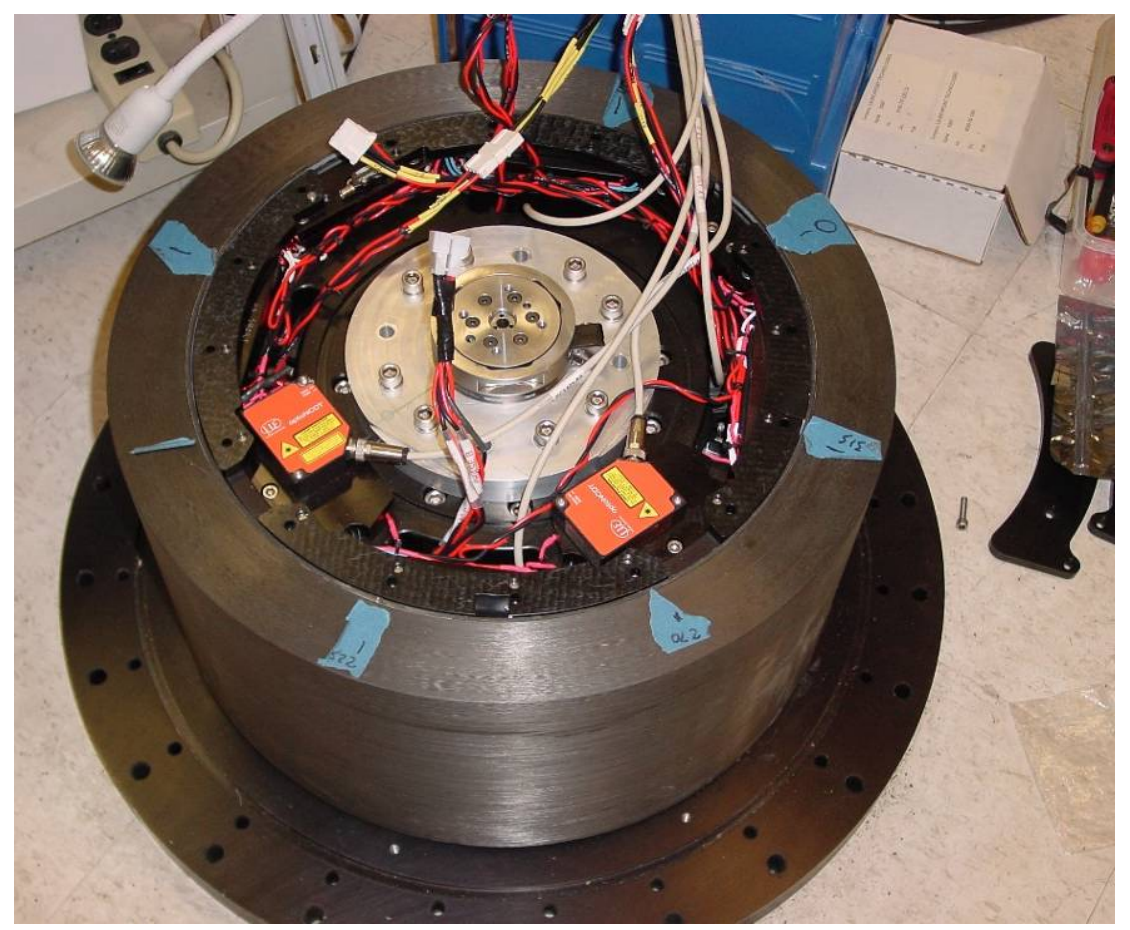

Figure 29 Demo Ring 


\section{Task 5. Testing}

Rim Structural Dynamics: Summary of Vibrational Modes Measured on Demonstration Power Ring

We measured the bare rim flexible mode frequencies by mounting the rim on a soft spring system and recording vibrational response to a small impact.

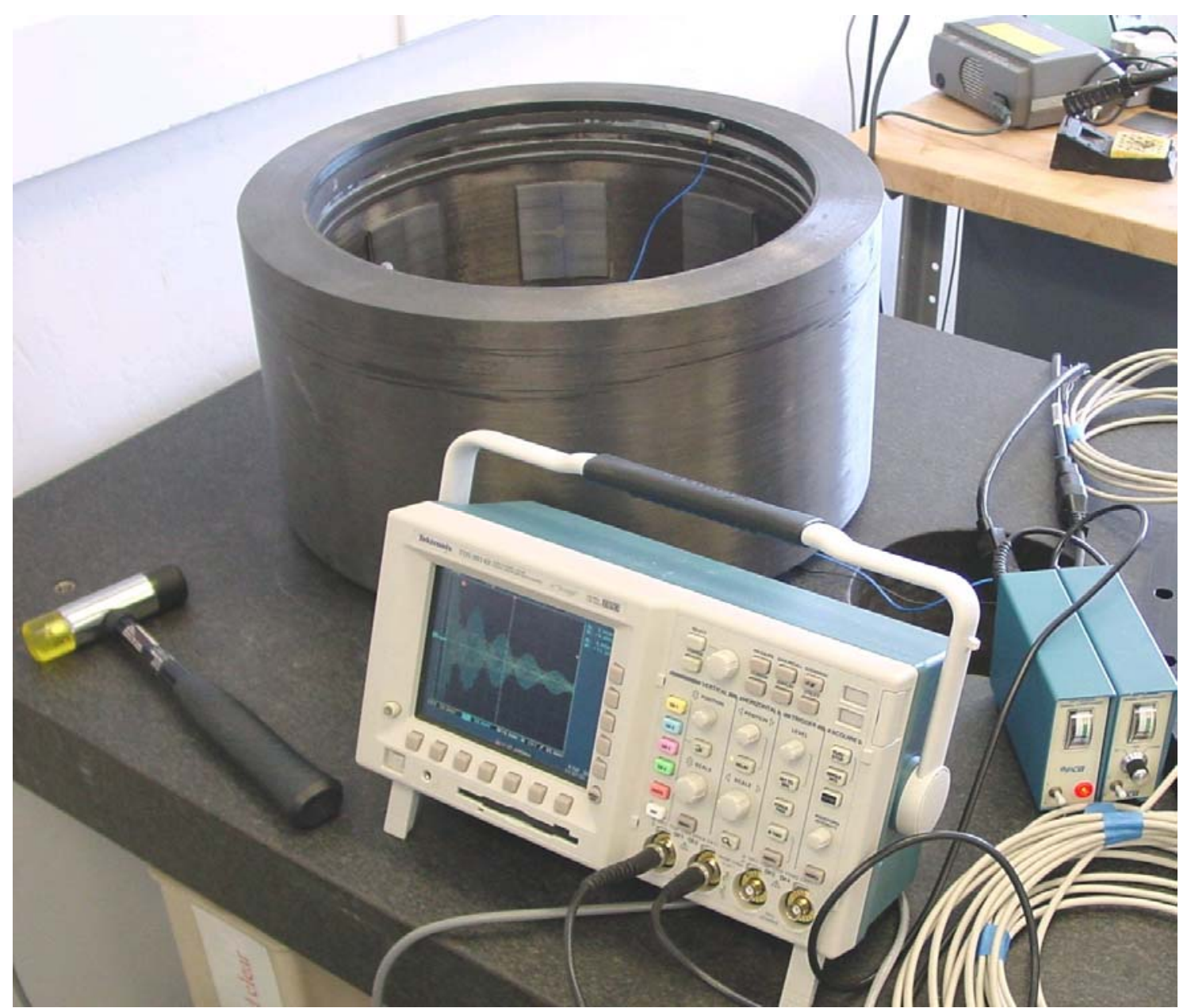

Figure 30: Experimental setup for measuring rim vibrational modes and modal damping. Rim is supported on soft springs and accelerometers are located at various points on the rim.

Accelerometers mounted on the Demonstration Power Ring (Toray 700 carbon fiber epoxy composite ring with ID = 16.0”, $\mathrm{OD}=20.0$ ” and height $=10.0$ ”) measured the following vibrations in response to an impulse. 


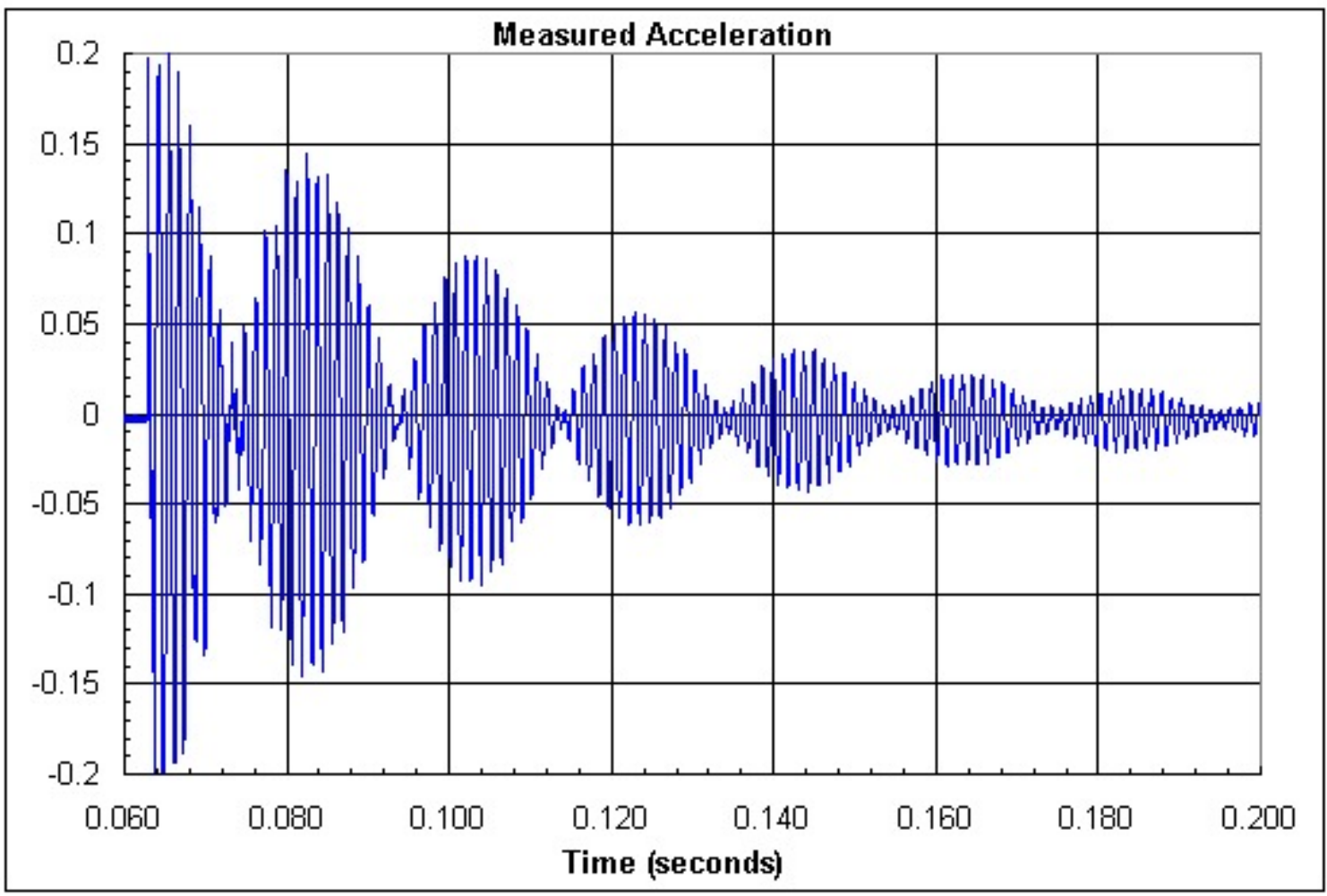

Figure 31. Measured acceleration on the Demonstration Power Ring clearly shows the beating and damping of the two lowest vibrational modes, and also suggests much higher frequency modes with faster damping are present in the first $\mathbf{0 . 0 3}$ seconds after the impulse. A faster sample rate would be needed to resolve the faster modes clearly.

A fit to the functional form

$$
A(t)=A_{0} e^{-t / \tau} \sin \left(\omega_{1} t-\phi_{1}\right)\left[c+\sin \left(\omega_{2} t-\phi_{2}\right)\right]
$$

identified the fast carrier wave frequency $\omega_{1}$, the beat wave frequency $\omega_{2}$, and the decay time $\tau$ of the lowest two vibrational modes. Function (1) can be rewritten as the sum of two independent vibrations,

$$
A(t)=A_{1} e^{-t / \tau} \sin \left[\left(\omega_{1}+\omega_{2}\right) t\right]+A_{2} e^{-t / \tau} \sin \left[\left(\omega_{1}-\omega_{2}\right) t\right]
$$

with the assumption that the faster mode with frequency $\omega_{1}+\omega_{2}$ has nearly the same damping time constant $\tau$ as the slower vibrational mode with frequency $\omega_{1}-\omega_{2}$. The two modes identified this way correspond reasonably well to the lowest frequency torsional mode and the lowest frequency in-plane bending mode of the Demonstration Power Ring as calculated by Finite Element Analysis (FEA). The table below compares the measured results for each mode in two cases - loaded with suspension magnets and unloaded - with the results of the FEA and the results of an analytic method that approximates the ring using a small number of interacting elements and the known elastic constants of the material. 


\begin{tabular}{|l|c|c|c|}
\hline \multicolumn{1}{|c|}{ Vibrational Mode } & Measured (Hz) & FEA (Hz) & Analytic Approx (Hz) \\
\hline $\begin{array}{l}\text { FEA “Mode 7” } \\
\text { Torsional n=2 mode } \\
\text { With no magnets }\end{array}$ & 760 & 828 & 1024 \\
\hline $\begin{array}{l}\text { FEA “Mode 7” } \\
\text { Torsional n=2 mode } \\
\text { With magnets }\end{array}$ & 768 & 727 & 878 \\
\hline $\begin{array}{l}\text { FEA “Mode 9” } \\
\text { In-plane bending mode n=2 } \\
\text { with no magnets }\end{array}$ & 828 & 930 & 906 \\
\hline $\begin{array}{l}\text { FEA “Mode 9” } \\
\text { In-plane bending mode n=2 } \\
\text { With magnets }\end{array}$ & 818 & 811 & 776 \\
\hline
\end{tabular}

Table 1: Comparison of measured vibrations with FEA and Analytic predictions

It is not surprising that the FEA predicts the actual mode frequencies more accurately than an oversimplified analytic model. The simple models predict that the first torsional mode will occur at about 10\% higher frequency than the first in-plane bending mode, but the FEA models correctly calculated that the torsional mode actually occurs at lower frequency. It is a little bit surprising that the torsional $n=2$ mode increases its frequency when the ring is loaded with magnets. This contradicts both the FEA and the analytic models, which predict a lower torsional vibration frequency as the mean material density increases. One likely explanation is that the addition of the magnets increases the torsional stiffness of the ring, an effect not included in the FEA or analytic models, and this greater stiffness results in a higher torsional frequency than the models predicted. Alternatively, the $8 \mathrm{~Hz}$ change in frequency is likely within the error bar of the frequency measurement. In general there is reasonably good agreement between the FEA and the measured data, such that we can confidently predict the lowest vibrational frequencies of any future Power Rings with better than 13\% accuracy. We note that these are the modes of greatest concern, because higher frequency modes are less likely to couple to excitation frequencies of the motor and suspension and will generally have much higher damping, as the measured data indicate.

\begin{tabular}{|cc|cc|cc|}
\hline \multicolumn{2}{|c|}{ Shell with Magnets } & \multicolumn{2}{|c|}{ Shell with no Magnets } & \multicolumn{2}{c|}{ Solid with no magnets } \\
\hline Mode 7 & $726.84 \mathrm{~Hz}$ & Mode 7 & $848.17 \mathrm{~Hz}$ & Mode 7 & $827.68 \mathrm{~Hz}$ \\
\hline Mode 8 & 726.85 & Mode 8 & 848.18 & Mode 8 & 827.74 \\
\hline Mode 9 & 810.67 & Mode 9 & 945.99 & Mode 9 & 929.62 \\
\hline Mode 10 & 810.67 & Mode 10 & 945.99 & Mode 10 & 929.69 \\
\hline Mode 11 & 1835.6 & Mode 11 & 2142 & Mode 11 & 2095.9 \\
\hline
\end{tabular}

Table 2: FEA Mode List for Demonstration Power Ring (Sep 7, 2006)

The damping coefficient at the lowest vibrational modes, as measured from the data fit, is $\eta=0.030$ (fractional amplitude loss per cycle) for the Demonstration Power Ring with no magnets, and $\eta=0.027$ with magnets. This is about three times higher damping than reported in Reference [1], probably because we are planning to operate at higher frequencies than most 
mechanical systems can tolerate. In general damping increases as frequency increases, and it is likely that J.H. Yim, et al made their damping measurements at lower frequencies. The experimental results agree with our intuition that adding the magnet material would increase damping in the rim structural system.

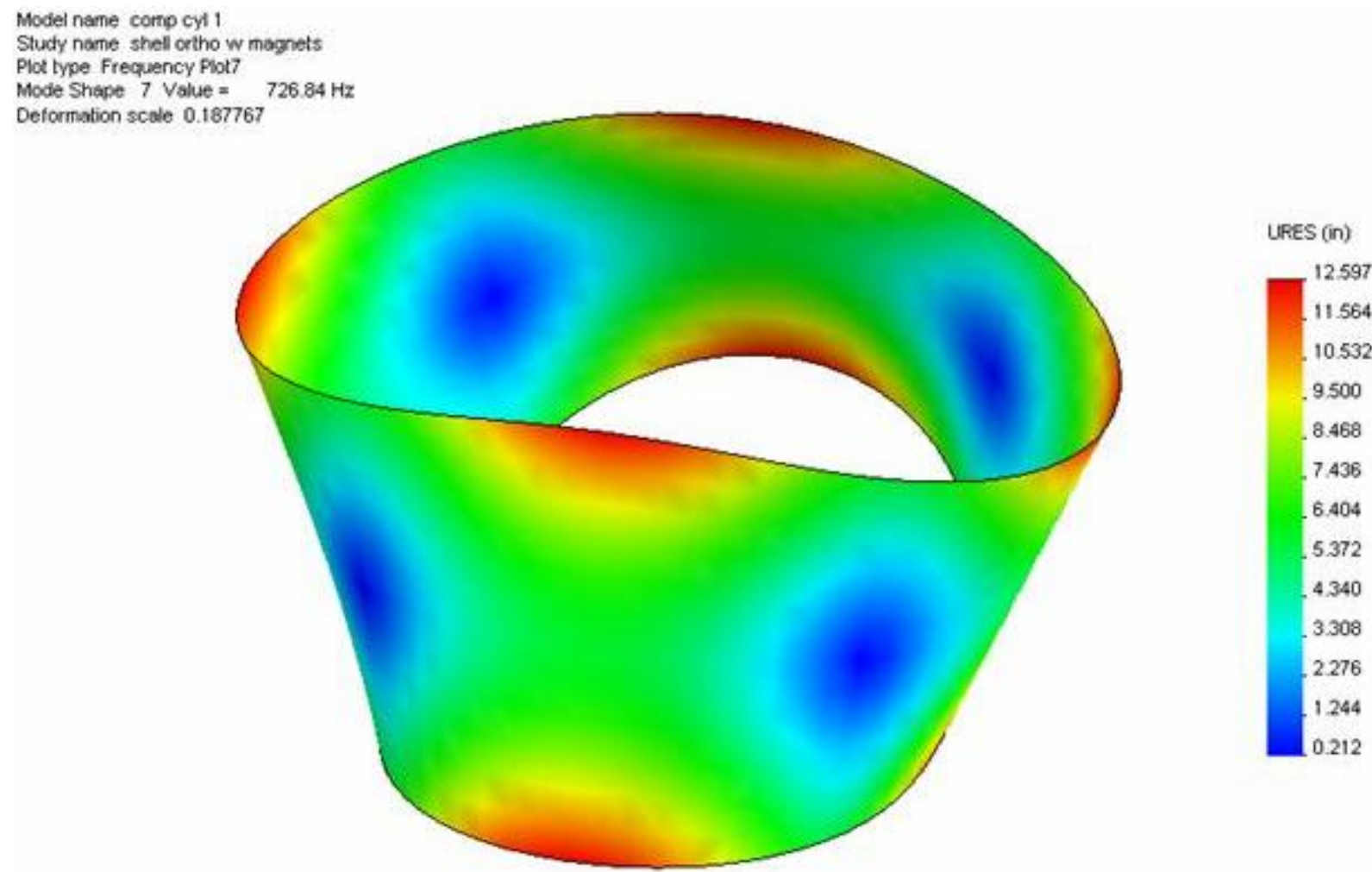

Figure 32: FEA Predicted Mode Shape 7, 8 (Torsional n=2 around the ring)

\section{References:}

[1] Yim, J.H., and Gillespie Jr., J.W., "Damping Characteristics of $0^{\circ}$ and 90 AS4/3501-6 Unidirectional Laminates Including the Transverse Shear Effect," Composite Structures, v50, 2000, pp. 217-225. 
Model name comp cyl 1

Study narne shell ortho w magnets

Plot type Frequency Plots

Mode Shape 9 Value $=810.67 \mathrm{~Hz}$

Deformation scale 0.29069

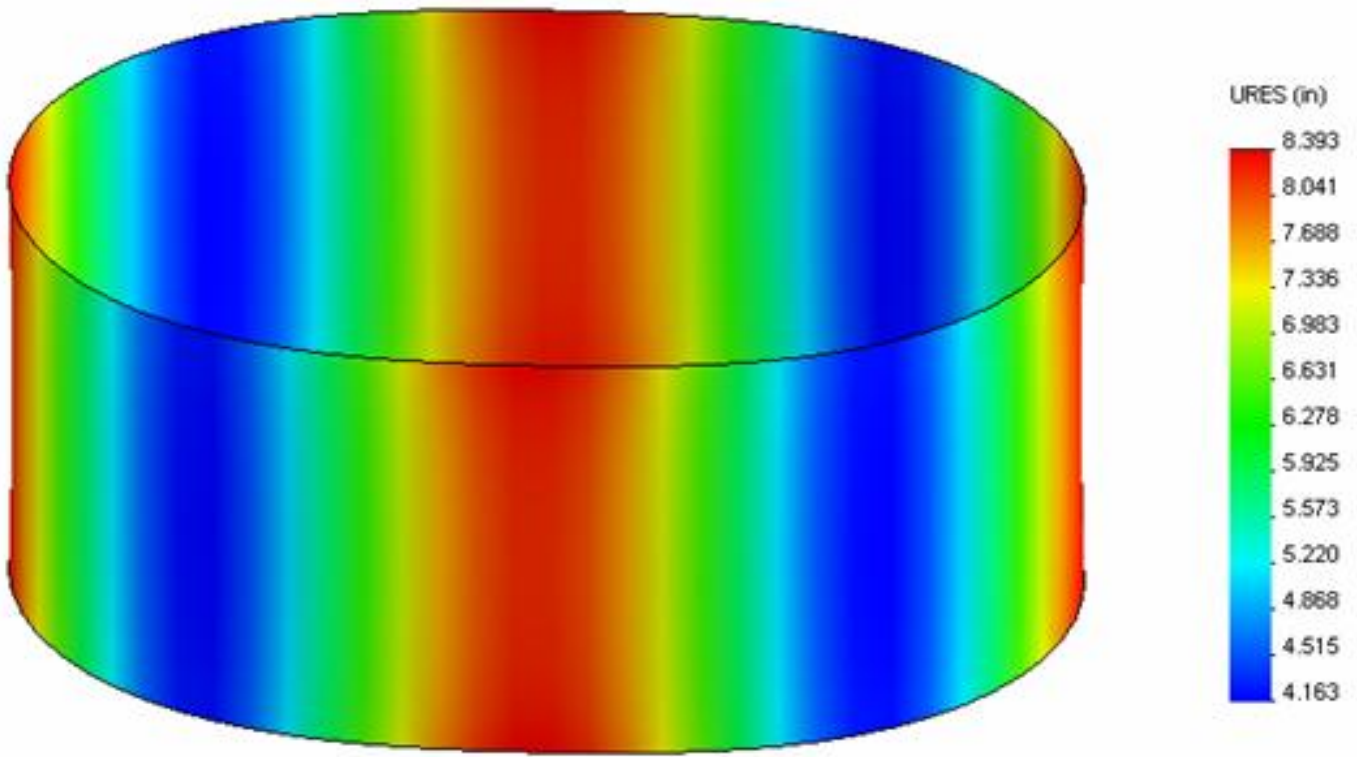

Figure 33: FEA Predicted Mode Shape 9,10 (In-plane bending n=2)

\section{Active Rim Levitation and Rotation:}

We received additional venture funding that allowed us to continue with the work and research into active levitation of the rim.

The rim was mounted onto the passive levitation magnets and the suspension held the rim at the predicted levitation height to within .010". We installed our "training wheels" that held the rim centered on the PM bearing while allowing the rim to rotate. With this setup we were able to rotate the rim by hand and verify that the system was indeed levitated and not touching or dragging on any surface other than the stabilizing wheels.

A special load cell fixture was attached to the stator and the training wheel structure to allow us to measure the PM bearing reaction forces. We made a measurement of the key PM bearing parameter which is the radial negative stiffness. Due to mechanical tolerance in the fixture the data obtained did not have a high accuracy, but it did agree with the predicted PM bearing negative stiffness within the expected error margins. 


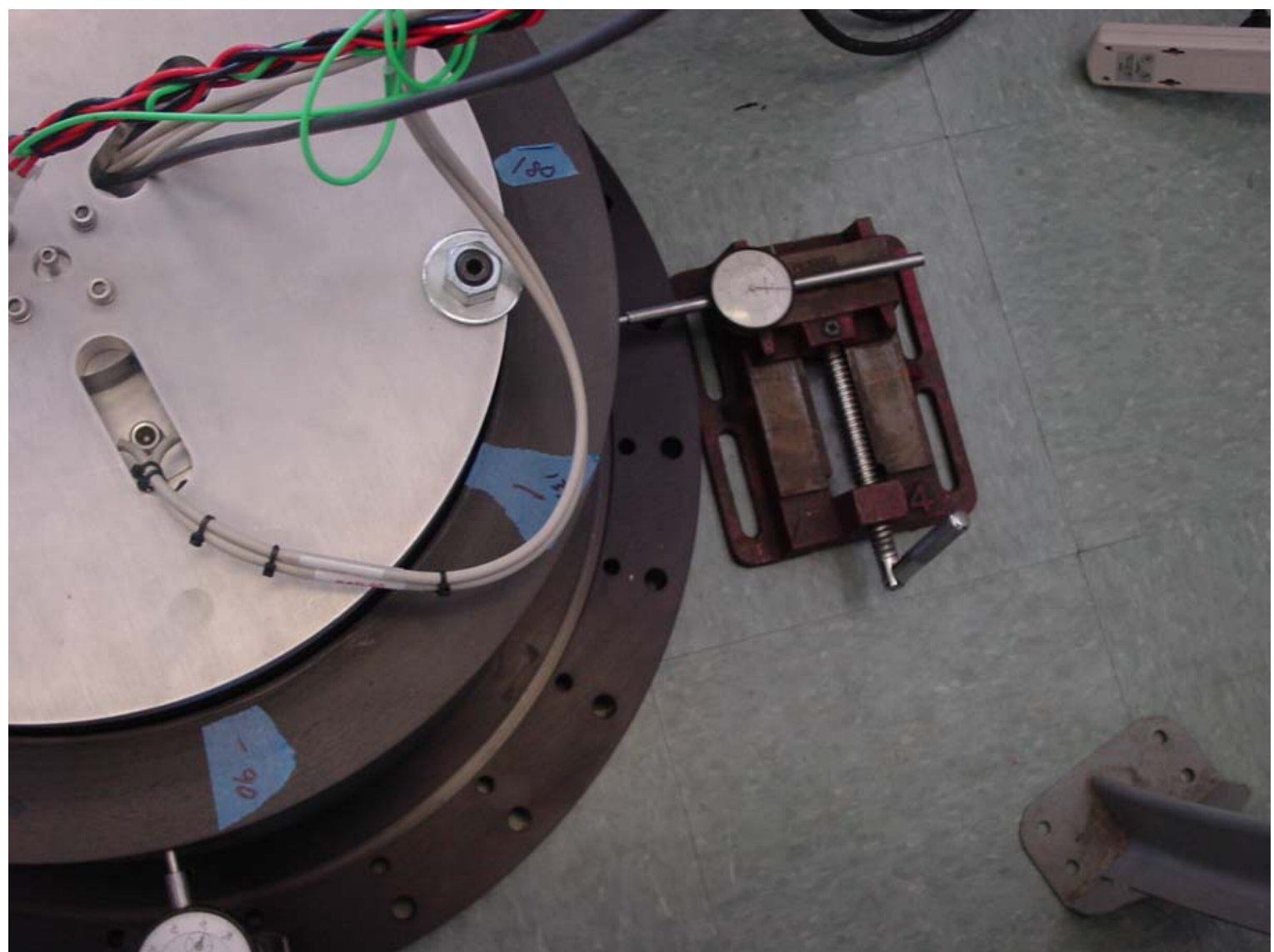

Figure 34: Bearing characterization fixture. Dial indicators measure the relative placement of the rim and a load cell (under the large aluminum plate) measures the bearing force onto the rim.

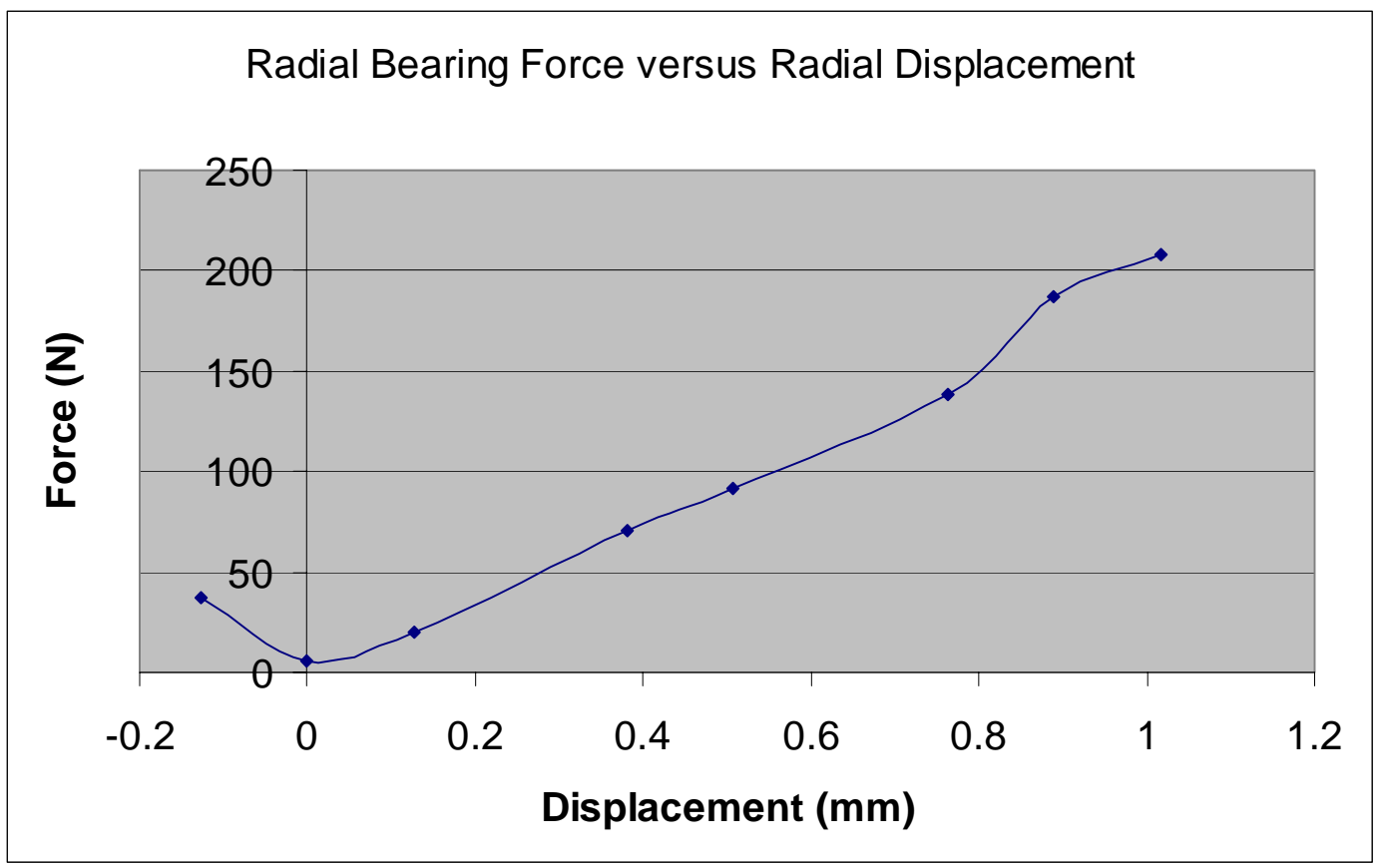

Figure 35: Measured bearing radial stiffness. (Susp Mag Radial Forces.xls) 
We finished designing the active levitation control system and sensing system, including the system schematic, wiring diagrams, and parts lists. We had to do some research to come up with the correct protection relays to keep a levitation coil from overheating and damaging the magnets in the event of a control system failure.

The levitation amplifiers, control system hardware, system rack, and other components were all purchased and the control system assembled. See Figure 28 Control rack.

For the system design simulations we had used a high order controller based on a Kalman estimator for the entire 10 DOF system (5 rigid body displacements and 5 velocities) with a full state feedback controller. Simulations of this controller allowed us to make estimates of system power requirements and system performance early in the design phase of the system. However, robustness analysis on this controller suggested that it would be very sensitive to uncertainty in the plant model, making it more useful as a system simulation analysis tool than as a real, experimental controller.

Since FEA, Mathcad predictions, and the experimental measurements of the bearing stiffness and cross coupling only agreed to within $50 \%$ or so, we did not have high confidence that our initial system model would be close enough that the high order Kalman filter controller would work.

\begin{tabular}{|l|l|l|l|}
\hline & \multicolumn{1}{|c|}{ Mathcad prediction } & \multicolumn{1}{|c|}{ FEA calculation } & \multicolumn{1}{|c|}{$\begin{array}{c}\text { Experimental } \\
\text { measurement }\end{array}$} \\
\hline Radial Stiffness & $250 \mathrm{~N} / \mathrm{mm}$ & $358 \mathrm{~N} / \mathrm{mm}$ & $195 \mathrm{~N} / \mathrm{mm}$ \\
\hline Tilt Stiffness & $3888 \mathrm{~N}^{*} \mathrm{~m} / \mathrm{rad}$ & $2565 \mathrm{~N}^{*} \mathrm{~m} / \mathrm{rad}$ & (NA) \\
\hline $\begin{array}{l}\text { Radial motion to } \\
\text { torque cross coupling }\end{array}$ & $14.17 \mathrm{~N}^{*} \mathrm{~m} / \mathrm{mm}$ & $22.3 \mathrm{~N}^{*} \mathrm{~m} / \mathrm{mm}$ & (NA) \\
\hline
\end{tabular}

Table 3: Comparison of bearing stiffness parameters estimated from different methods.

Our plan was to devise a simpler, more robust controller that would have lower performance but would be easier to initially tune to achieve levitation. Once levitation was achieved we would use system ID techniques to use the system to measure itself to come up with a good measurement of the plant, at which point a new high order, high performance controller could be developed using the detailed system ID measurements of the plant.

The initial simplified controller used was a simple PID controller on the $\mathrm{X}$ and $\mathrm{Y}$ rigid body motions, a damping only controller on the tilt motions, and no control on the $\mathrm{Z}$ axis. With this controller we were able to hand-tune values to achieve levitation. Even with the best handtuned parameters, we found that the control loop was only marginally stable, and had significant power consumption due to system noise and oscillation. 


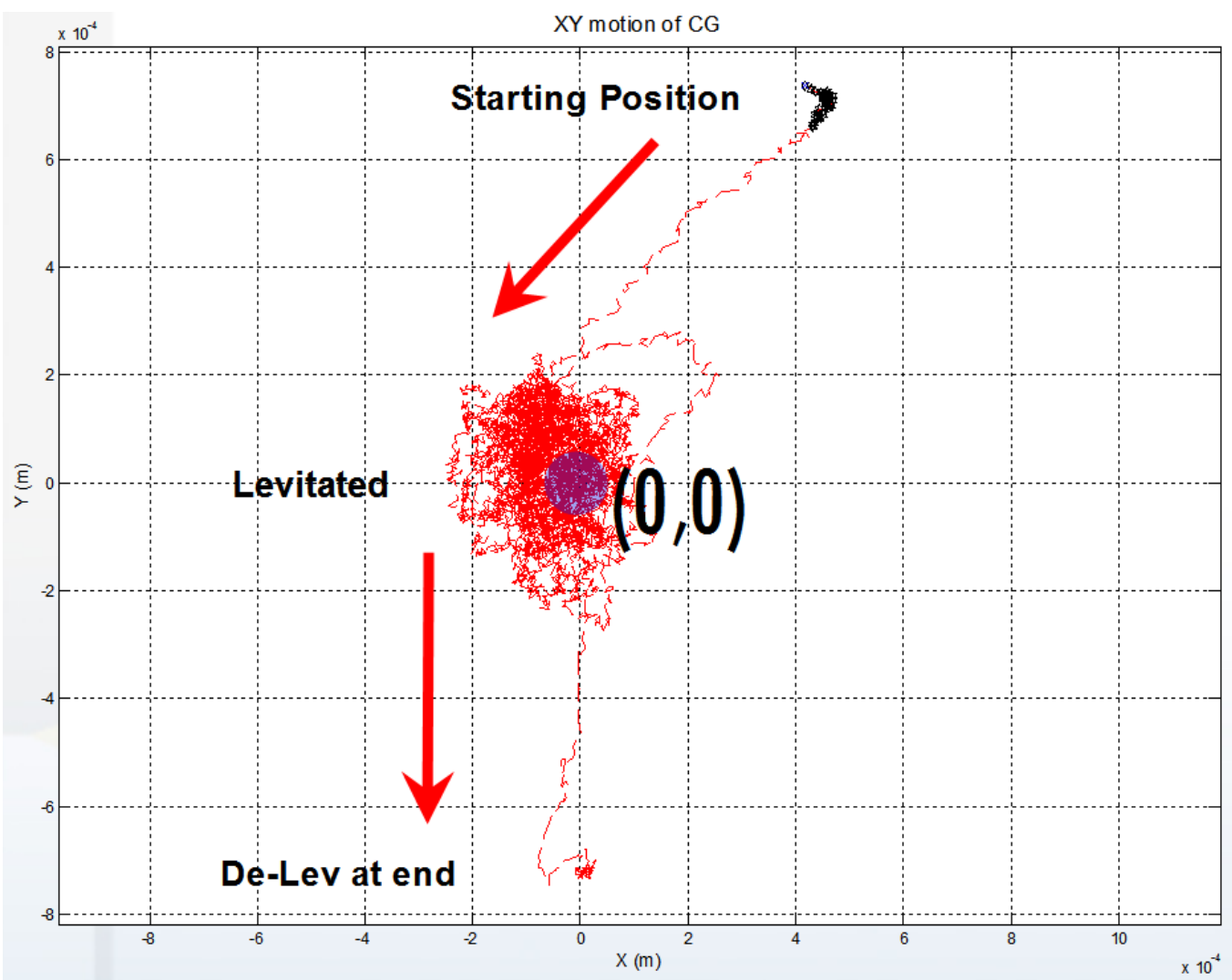

Figure 36: X-Y trajectory of rim center of gravity (CG) during launch, levitation, and de-levitation. Launch is across almost a $1 \mathrm{~mm}$ gap, levitation holds the CG within a $.2 \mathrm{~mm}$ radius circle.

Our data acquisition system for the controller was being badly polluted by noise from the amplifiers used for the levitation actuators. The noise pickup is in the DAQ card connections, not in the sensors themselves. We were able to run the sensors in a digital mode and almost completely eliminated the noise problem, but levitation was actually made more difficult with the digital sensors.

After much research and debugging we discovered that the $500 \mathrm{~Hz}$ optical distance sensors we were using in the control loop had a 3 sample period "processing delay" from when they took a distance measurement to when they output the position signal. In digital sensor mode, this delay is further increased due to the serial data transmission time. System ID data on the marginally stable system and further analysis showed that this delay (which was not documented in the unit's data sheet) adds so much phase lag that the system is only marginally stabilizable with very poor gain and phase margins. Future work (in progress) will replace the sensors with new ones that have negligible processing delay, which will allow higher closed loop bandwidth and a more robust control system.

Despite the marginal control loop stability, we were able to rotate the rim while levitated. Initially the rim was rotated by small hand pushes., but we have also built a prototype motor drive and used the VR motor built into the rim to rotate while levitated. We have not yet achieved significant speeds, but we have demonstrated that the suspension system works while the rim is rotated with the motor. 


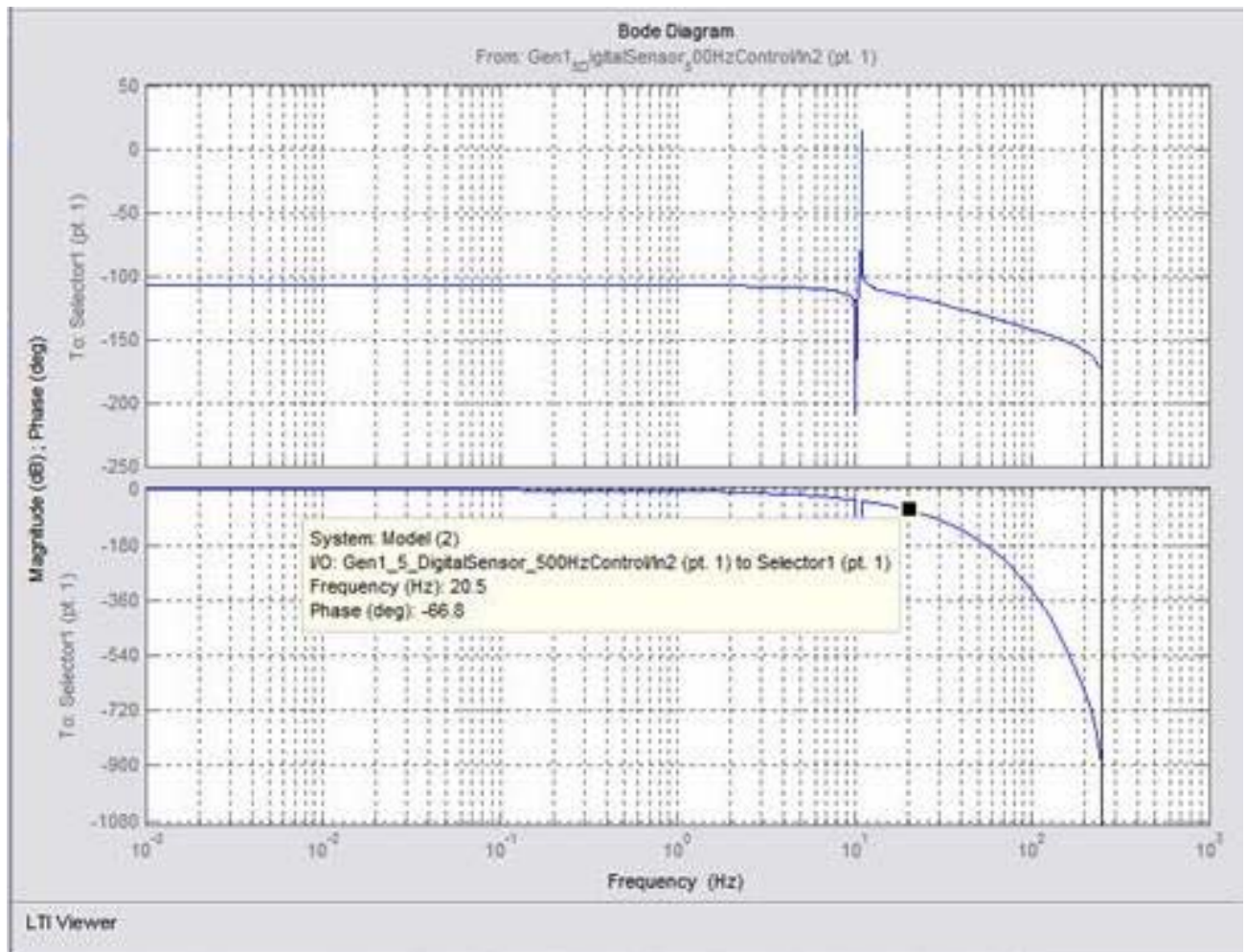

Figure 37: Plant transfer function - $X$ force to measured $X$ displacement. Note that by $20 \mathrm{~Hz}$ there is already 67 degrees of lag due to the sensor system delays. It was only possible to close the loop at approximately 12 $\mathrm{Hz}$, giving a phase margin of around 12 degrees and a gain margin of only a few $\mathrm{dB}$; clearly not acceptable for a highly robust system. New sensors will remove the phase lag and allow loop closure at much higher bandwidth and robustness

\section{Conclusions and recommendations for future work} workable.

We have demonstrated that the Power Ring suspension system concept is viable and

With the additional venture funding we have received we are purchasing new sensors that will be faster, and more importantly will have almost no processing delay. The reduced processing delay will move the phase roll-off due to delay up almost a decade from its present location, and allow us to achieve a controller that (in the SISO sense) has acceptable phase and gain margins. We expect that this will allow a much more robust control loop to be realized and we will achieve acceptable rim rotation speeds with the motor.

A containment system will be added to protect personnel from the moving component of the system, and we will attempt to spin the present rim at much higher speeds, up to $40 \mathrm{or} 50 \mathrm{~Hz}$ rotation. These speeds will allow us to demonstrate supercritical operation of the suspension system. While this will still not provide the high energy capacity we plan to achieve, the surface speeds will be in excess of $50 \mathrm{~m} / \mathrm{s}$ (we eventually will reach $600 \mathrm{~m} / \mathrm{s}$ or more).

The final step will be to fabricate a new rim using appropriate techniques that will allow the rim structure and magnet bonds to survive the high stress levels at the ultimate speed of 600+ $\mathrm{m} / \mathrm{s}$ surface speed. The unit will be taken to a burst containment facility and high speed testing will commence. 


\section{Appendix A. Final Task Schedule}

\begin{tabular}{|c|c|c|c|c|c|c|}
\hline \multirow{2}{*}{$\begin{array}{c}\text { Task } \\
\text { Number }\end{array}$} & \multirow[b]{2}{*}{ Task Description } & \multicolumn{4}{|c|}{ Task Completion Date } & \multirow[b]{2}{*}{ Progress Notes } \\
\hline & & $\begin{array}{l}\text { Original } \\
\text { Planned }\end{array}$ & $\begin{array}{l}\text { Revised } \\
\text { Planned }\end{array}$ & Actual & $\begin{array}{l}\text { Percent } \\
\text { Complete }\end{array}$ & \\
\hline $1 \mathrm{a}$ & $\begin{array}{c}\text { Preliminary Study-- } \\
\text { Develop Operation Specs } \\
\end{array}$ & $9 / 1 / 05$ & 9/1/05 & 9/1/05 & $100 \%$ & Complete. \\
\hline $1 b$ & $\begin{array}{l}\text { Preliminary Study-- } \\
\text { Rotordynamics Analysis }\end{array}$ & $10 / 31 / 05$ & $6 / 1 / 06$ & 8/31/06 & $100 \%$ & Complete \\
\hline $2 a$ & $\begin{array}{c}\text { Sub Scale Test Unit } \\
\text { Design--Spec, Size Ring }\end{array}$ & $2 / 1 / 06$ & $5 / 28 / 06$ & $6 / 30 / 06$ & $100 \%$ & Complete. \\
\hline $2 b$ & $\begin{array}{c}\text { Sub Scale Test Unit } \\
\text { Design--Levitation Design }\end{array}$ & $2 / 1 / 06$ & $8 / 4 / 06$ & $9 / 30 / 06$ & $100 \%$ & Complete. \\
\hline $2 c$ & $\begin{array}{c}\text { Sub Scale Test Unit } \\
\text { Design--Actuator Design }\end{array}$ & $2 / 1 / 06$ & $8 / 4 / 06$ & $9 / 30 / 06$ & $100 \%$ & Complete. \\
\hline $2 d$ & $\begin{array}{c}\text { Sub Scale Test Unit } \\
\text { Design--Sensor Design }\end{array}$ & $2 / 1 / 06$ & $8 / 25 / 06$ & $1 / 2 / 2007$ & $100 \%$ & Complete. \\
\hline $2 e$ & $\begin{array}{c}\text { Sub Scale Test Unit } \\
\text { Design--Control System } \\
\text { Design }\end{array}$ & $4 / 1 / 06$ & $4 / 15 / 07$ & $8 / 1 / 07$ & $100 \%$ & Complete \\
\hline $2 f$ & $\begin{array}{l}\text { Sub Scale Test Unit } \\
\text { Design--CAD layout }\end{array}$ & $4 / 1 / 06$ & $2 / 16 / 07$ & $2 / 16 / 07$ & $100 \%$ & Complete. \\
\hline $2 g$ & $\begin{array}{l}\text { Sub Scale Test Unit } \\
\text { Design--CAD details }\end{array}$ & $4 / 1 / 06$ & $5 / 15 / 07$ & $6 / 16 / 07$ & $100 \%$ & Complete. \\
\hline $2 \mathrm{~h}$ & $\begin{array}{c}\text { Sub Scale Test Unit } \\
\text { Design--Safety Shield }\end{array}$ & $4 / 1 / 06$ & $6 / 1 / 07$ & $6 / 1 / 07$ & $100 \%$ & Complete \\
\hline 3 & Prototype Fabrication & $10 / 1 / 06$ & $5 / 15 / 07$ & $6 / 15 / 07$ & $100 \%$ & Complete \\
\hline 4 & Prototype Assembly & 12/1/06 & $6 / 1 / 07$ & $2 / 1 / 08$ & $100 \%$ & Complete \\
\hline 5 & Testing & $6 / 1 / 07$ & $7 / 1 / 07$ & $5 / 1 / 08$ & $100 \%$ & Complete \\
\hline
\end{tabular}




\section{Appendix B. Final Spending Schedule}

Project Period: $8 / 1 / 2005$ to $7 / 31 / 2007$

Spending Schedule

Current Quarter: 07/01/2007 to 07/31/2007

\begin{tabular}{|c|c|c|c|}
\hline \multirow{2}{*}{ Task } & \multirow{2}{*}{$\begin{array}{l}\text { Approved } \\
\text { Budget }\end{array}$} & \multicolumn{2}{|c|}{ Project Expenditures } \\
\hline & & This Quarter & Cumulative to Date \\
\hline Task 1 Preliminary Study & 33,628 & 0 & 5,931 \\
\hline Task 2 Sub Scale Test Unit Design & 59,687 & 0 & 80,985 \\
\hline Task 3 Prototype Fabrication & 70,912 & 0 & 85,901 \\
\hline Task 4 Prototype Assembly & 23,833 & 0 & 39,382 \\
\hline Task 5 Testing & 46,313 & 13,508 & 22,174 \\
\hline Total & 234,373 & 13,508 & 234,373 \\
\hline DOE Share & 234,373 & 13,508 & 234,373 \\
\hline
\end{tabular}

\section{Appendix C. Final Cost Share Contributions}

Our original proposal contained no cost-sharing as we had not yet been able to find the appropriate venture partner. With the progress that resulted from DOE grant-funded work we were able to raise additional funding in the fall of 2007. This funding allowed us to continue and finish the work originally proposed for the grant. To date $\$ 450,000$ of venture funding has been invested in continuation of the research started with this grant.

\begin{tabular}{|c|c|c|c|c|}
\hline \multirow{2}{*}{ Funding Source } & \multicolumn{2}{|c|}{ Approved Cost Share } & \multicolumn{2}{c|}{ Final Contributions } \\
\cline { 2 - 5 } & Cash & In-Kind & Cash & In-Kind \\
\hline PowerRing LLC & 0 & & $\$ 450,000$ & \\
\hline & & & & \\
\hline Total & 0 & 0 & $\$ 450,000$ & 0 \\
\hline \multicolumn{5}{|r|}{} \\
\hline Cumulative Cost Share Contributions & $\$ 450,000$ \\
\hline
\end{tabular}




\section{Appendix D. Energy Savings Metrics}

\section{Frequency Regulation}

The utility electric power grid must address two unique requirements: the need to maintain a near real-time balance between generation and load, and the need to adjust generation (or load) to manage power flows through individual transmission facilities. Frequency Regulation, or simply "Regulation”, and load following are the two power grid services required to continuously balance generation and load under normal conditions (Kirby and Hirst 2000). Figure 38 shows the morning ramp-up of a local power grid decomposed into the Load Following provided by power plant generators (blue), Regulation (red), and Total Load (green) (Kirby 2004). Starting at a base energy of $3566 \mathrm{MW}$, the smooth load following ramp is shown rising to $4035 \mathrm{MW}$. Regulation consists of rapid fluctuations in supply, shown here on an expanded scale to the right with a $\pm 55 \mathrm{MW}$ range. Combined, these elements serve a load that ranges from 3539 to 4079 MW during the three hours depicted.

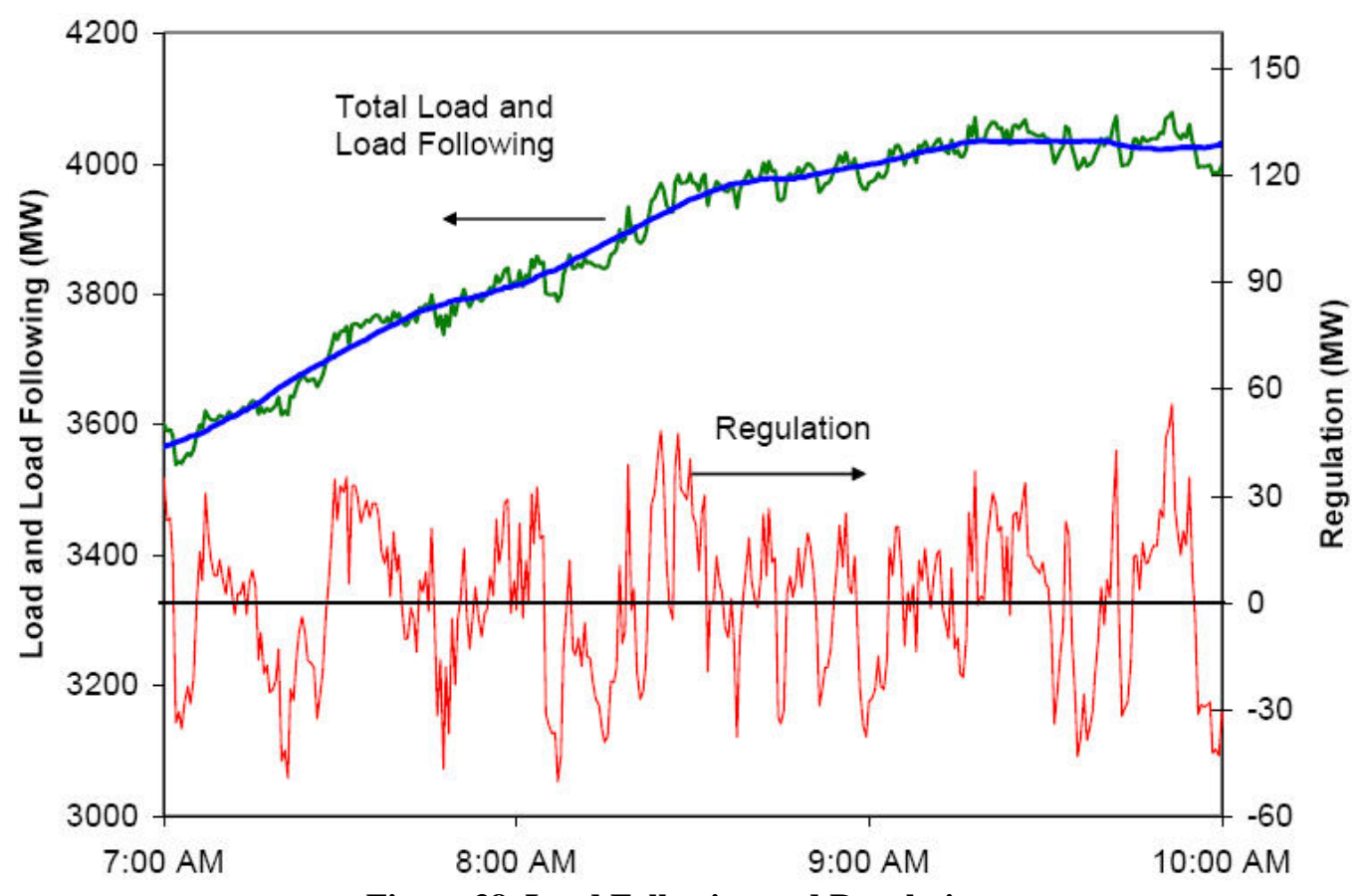

Figure 38 Load Following and Regulation

Balancing generation and load instantaneously and continuously is difficult because loads and generators are constantly fluctuating. Minute-to-minute load variability results from the random activation/deactivation of millions of individual loads. Longer-term variability results from predictable factors such as the daily and seasonal load patterns as well as more random events like shifting weather patterns. Generators also introduce unexpected fluctuations because they do not follow their generation schedules exactly and sometimes trip unexpectedly due to a range of equipment failures. The output from wind generators varies with the wind.

Load following and Regulation ensure that, under normal operating conditions, a control area is able to balance generation and load. Load following is the use of on-line generation, storage, or load equipment to track the intra- and inter-hour changes in customer loads. 
Regulation is the use of on-line generation, storage, or load that is equipped with automatic generation control (AGC) and that can change output quickly (MW/min) to track the moment-tomoment fluctuations in customer loads and to correct for the unintended fluctuations in generation. Regulation helps to maintain interconnection frequency, manage differences between actual and scheduled power flows between control areas, and match generation to load within the control area. The goal is to keep the system at $60 \mathrm{~Hz}$ (in the US and some other countries, $50 \mathrm{~Hz}$ elsewhere). Excessive frequency shifts caused by load/generation imbalances put excessive strain on some types of industrial equipment and have been linked to significant blackout events.

Particularly for large power plants, changes in generator output are slow and can lag load variations by minutes, so ISO’s (Independent System Operators) and RTO’s (Regional Transmission Organizations) buy Regulation to minimize the load/output discrepancy. Regulation is classified as an Ancillary Service, and uses an open market Dutch Auction bid system to set prices. The ISO or RTO determines how much Regulation it will need the following day and asks for bids from Regulation providers. It then sorts the bids and energy amounts from lowest to highest and takes the bids from the bottom of the list until its energy quota is filled. The price of the highest bid that is "under the line" is called the marginal price and gets paid to all of the bidders. In general, Regulation prices typically range from $\$ 10-50$ per megawatt-hour (averaged for 24 hours), which corresponds to a yearly value of $\$ 87-438 \mathrm{k}$ per megawatt. Extrapolated over the rest of the country, these prices imply a total yearly market for Regulation of $\$ 964$ million to $\$ 4.8$ billion. With the cost of electricity even higher in most of the rest of the world, the foreign market could be even larger.

Regulation has two components-Up Regulation and Down Regulation. Up Regulation is required when the grid supply is lower than demand. At present, power plant capacity is held in reserve and applied as needed to provide Up Regulation. That reserve capacity cannot be used to provide baseload power. Down Regulation is required when the grid supply is higher than demand. In order to provide Down Regulation, a fast-reacting power plant must be supplying power to the grid. For example, if a gas-fired power plant capable of providing $20 \mathrm{MW}$ is currently supplying $10 \mathrm{MW}$ to the grid, it can provide $10 \mathrm{MW}$ of Up Regulation by increasing output to $20 \mathrm{MW}$, or it can provide $10 \mathrm{MW}$ of Down Regulation by decreasing output to zero.

One of the most important motivations for adding flywheel Regulation to the grid is the rapid increase in the use of wind power. According to Kirby (Frequency Regulation Basics and Trends, ORNL/TM-2004/291, December 2004), "The proliferation of renewable portfolio standards and the maturing of wind technology (with decreasing costs, higher availability, and greater reliability) is resulting in increased amounts of wind power. One of the few drawbacks to wind is the unpredictability and variability of the power output. Aggregation, both among wind turbines within wind plants and with the overall control area load, greatly reduces the regulation impact. Still, wind power does increase regulation needs. Wind also displaces conventional generation, often the marginal generators that provide regulation. The increase in distributed generation and cogeneration similarly displace marginal conventional generation with resources that are unable to supply regulation. These factors will increase the need for new technologies to supply regulation.”

As a metric of particular relevance for the future, we will use $1 \mathrm{MW}$ of Regulation (Up or Down).

- One Unit of Proposed Technology: $1 \mathrm{MW}$ of Regulation for 15 minutes (250 kWh of storage) using Power Rings. 
One Unit of Current Technology: 1 MW of Regulation using gas-fired generation.

\section{Discussion of Energy Savings:}

In order to provide $1 \mathrm{MW}$ of either Up or Down Regulation, on demand, a gas-fired generator must provide $1 \mathrm{MW}$ of power output, on average. Thus it consumes the energy required to produce a continuous $1 \mathrm{MW}$ of power.

- Gas-fired generator energy usage: $1 \mathrm{MW}$ x 8760 hr/yr x 10,500 Btu/kWh = 92 billion Btu/yr

Power Rings, on the other hand, can provide Down Regulation by absorbing power from the grid, and Up Regulation by releasing power to the grid, with a net energy usage, over time, of zero, plus the small amount of energy required to compensate for efficiency losses and operation of the units. Assuming one complete 15-minute charge and discharge cycle every hour, on average, with $5 \%$ power losses on both charge and discharge, Power Ring energy usage is 25 $\mathrm{kWh}$ due to losses (50 kW for 30 minutes) plus $25 \mathrm{kWh}$ per hour to operate the units (stabilization coils, control processor, power electronics, etc.), based on early design estimates.

- Power Ring energy usage: $50 \mathrm{kWh} / \mathrm{hr}$ x $8760 \mathrm{hr} / \mathrm{yr}$ x 10,500 Btu/kWh = 4.6 billion Btu/yr

Energy savings $=87.4 \mathrm{BBtu} / \mathrm{yr} / \mathrm{MW}$ of Regulation

\section{Energy Savings Metrics}

\begin{tabular}{|c|c|c|c|c|c|}
\hline & A & B & $C=A-B$ & D & $E=C x D$ \\
\hline $\begin{array}{c}\text { Type of Energy } \\
\text { Used }\end{array}$ & $\begin{array}{c}\text { Current } \\
\text { Technology } \\
\text { (Btu / yr / unit) }\end{array}$ & $\begin{array}{c}\text { Proposed } \\
\text { Technology } \\
\text { (Btu / yr / unit) }\end{array}$ & $\begin{array}{c}\text { Energy } \\
\text { Savings } \\
\text { (Btu / yr / unit) }\end{array}$ & $\begin{array}{l}\text { Estimated } \\
\text { Number of } \\
\text { Units in U.S. } \\
\text { by } 2010 \\
\text { (units) }\end{array}$ & $\begin{array}{c}\text { Energy Savings } \\
\text { by } 2010 \\
\text { (Btu / yr) }\end{array}$ \\
\hline Natural Gas & 92 Billion & & & & \\
\hline $\begin{array}{c}\text { Electricity (@ } \\
\text { 10,500 Btu / kWh) }\end{array}$ & & 4.6 Billion & & & \\
\hline Total Per Unit & 92 billion & 4.6 billion & 87.4 billion & 0 & 0 \\
\hline
\end{tabular}

Power Rings will not be in production by 2010, so energy savings shown above are zero. If energy savings from future production are estimated, however, the effects become substantial.

\begin{tabular}{|l|c|c|c|c|c|}
\hline Year & 2011 & 2012 & 2013 & 2014 & 2015 \\
\hline Average MW in operation & 10 & 50 & 100 & 200 & 400 \\
\hline Energy saved/yr (BBtu) & 874 & 4,370 & 8,740 & 17,480 & 34,960 \\
\hline Total energy saved (BBtu) & 874 & 5,244 & 13,984 & 31,464 & 66,424 \\
\hline & & & & & \\
\hline Energy saved/MW/yr (Brillion Btu) & 87.4 & & & & \\
\hline
\end{tabular}




\section{Supplemental Information}

\begin{tabular}{|c|c|c|c|c|c|c|c|}
\hline \multicolumn{8}{|c|}{ Project Spending and Estimate of Future Spending } \\
\hline $\begin{array}{l}\text { Calendar } \\
\text { Year } \\
\text { Quarter }\end{array}$ & From & To & $\begin{array}{l}\text { Estimated } \\
\text { Federal } \\
\text { Share of } \\
\text { Outlays* }\end{array}$ & $\begin{array}{l}\text { Actual } \\
\text { Federal } \\
\text { Share of } \\
\text { Outlays } \\
\end{array}$ & $\begin{array}{l}\text { Estimated } \\
\text { Recipient } \\
\text { Share of } \\
\text { Outlays* }\end{array}$ & $\begin{array}{l}\text { Actual } \\
\text { Recipient } \\
\text { Share of } \\
\text { Outlays } \\
\end{array}$ & $\begin{array}{l}\text { Cumulative } \\
\text { Actual } \\
\text { Outlays } \\
\text { (Federal + } \\
\text { Recipient) } \\
\end{array}$ \\
\hline & $8 / 1 / 05$ & $7 / 31 / 07$ & Note 1 & Note 3 & Note 1 & Note 3 & Note 3 \\
\hline 3Q05 & $7 / 1 / 05$ & $9 / 30 / 05$ & $\$ 5,930.52$ & $\$ 5,930.52$ & 0 & 0 & $\$ 5,930.52$ \\
\hline 4Q05 & 10/1/05 & $12 / 31 / 05$ & $\$ 5,677.53$ & $\$ 5,677.53$ & 0 & 0 & $\$ 5,677.53$ \\
\hline 1Q06 & $1 / 1 / 06$ & $3 / 31 / 06$ & $\$ 13,456.16$ & $\$ 13,457.07$ & 0 & 0 & $\$ 13,457.07$ \\
\hline 2Q06 & $4 / 1 / 06$ & $6 / 30 / 06$ & $\$ 26,072.26$ & $\$ 26,072.26$ & 0 & 0 & $\$ 26,072.26$ \\
\hline 3Q06 & $7 / 1 / 06$ & $9 / 30 / 06$ & $\$ 20,766.38$ & $\$ 20,766.38$ & 0 & 0 & $\$ 20,766.38$ \\
\hline 4Q06 & 10/1/06 & $12 / 31 / 06$ & $\$ 12,205.79$ & $\$ 12,205.79$ & 0 & 0 & $\$ 12,205.79$ \\
\hline 1Q07 & $1 / 1 / 07$ & $3 / 31 / 07$ & $\$ 60,439.86$ & $\$ 60,439.86$ & 0 & 0 & $\$ 60,439.86$ \\
\hline 2Q07 & $4 / 1 / 07$ & $6 / 30 / 07$ & $\$ 76,315.43$ & $\$ 76,315.43$ & 0 & 0 & $\$ 76,315.43$ \\
\hline 3Q07 & $7 / 1 / 07$ & $7 / 31 / 07$ & $\$ 13,509.07$ & $\$ 13,509.07$ & 0 & 0 & $\$ 13,509.07$ \\
\hline Totals & & & $\$ 234,373.00$ & $\$ 234,373.00$ & 0 & 0 & $\$ 234,373.00$ \\
\hline
\end{tabular}

* Update quarterly

General Note: The information in this table should be consistent with the information provided in section 10 of the quarterly financial status reports (SF269 or SF269A).

Note 1: Leave blank. Only the actual DOE/Cost Share amounts spent through the latest completed quarter are needed.

Note 2: Amount for this quarter and subsequent quarters should be updated as necessary on a quarterly basis. Estimates need to be provided for the entire project. If spending for a given quarter is different than estimated, then the remaining quarter's estimates should be updated to account for the difference. Total DOE and Cost Share amounts should be the same as the Award amount.

Note 3: This amount is the same as submitted last quarter on the quarterly financial status reports (SF269 or SF269A). 